\title{
Neutron Spectrometry*
}

\author{
A. V. ALEVRA**
}

(Manuscrit reçu le 18 mars 1999, accepté le 19 mars 1999)

\begin{abstract}
A few neutron field spectrometry techniques are presented, namely those having impact on neutron dosimetry and using active detectors: spectrometry using recoil-proton techniques (liquid scintillation spectrometer and proportional counter) or ${ }^{3} \mathrm{He}$-filled proportional counters, as well as spectrometry using moderator techniques (Bonner spheres). Results obtained with these techniques are shown and compared. It is concluded that in most cases, at least when radiation protection applications alone are of interest, it is sufficient to use a Bonner sphere spectrometer.

RÉSUMÉ Spectrométrie des neutrons.

Quelques techniques de spectrométrie des neutrons sont présentées, notamment celles qui peuvent être utilisées pour la dosimétrie des neutrons et mettent en ouvre des détecteurs actifs : des techniques de spectrométrie par protons de recul (scintillateurs liquides ou compteurs proportionnels), des compteurs proportionnels remplis de ${ }^{3} \mathrm{He}$ et la technique des modérateurs sphériques (sphères de Bonner). Des résultats obtenus avec ces techniques sont présentés. La comparaison de ces résultats montre que dans la plupart des cas, ou du moins dans les cas où l'interêt se borne à des applications en radioprotection, l'utilisation seule d'un spectromètre multisphères est suffisante.
\end{abstract}

\section{Introduction}

Neutrons with which we are concerned, either those from natural sources or those produced by human activities, cover a wide energy range extending from $1 \mathrm{meV}$ (or less) to hundreds of $\mathrm{MeV}$ (or more). As examples, three neutron spectra are shown in Figure 1, measured a) within the containment of a pressurised water reactor (Alevra, 1995), b) near a transport cask filled with spent nuclear fuel elements (Alevra, 1995), and c) at CERN, behind a thick concrete shielding, a neutron field

* Cet article représente la version détaillée en anglais de la communication faite en français le jeudi 5 novembre 1998 dans le cadre des journées sur «LA DOSIMÉTRIE DES NEUTRONS» organisées par la section de protection technique de la société française de radioprotection, à l'INSTN - Centre de Cadarache.

** Physikalisch-Technische Bundesanstalt (PTB), Secion 6.42 Bundesallee 100, 38116 Braunschweig. Federal Republic of Germany. 
adequate to simulate the spectral distribution of the neutrons induced by cosmic rays in the atmosphere (Alevra et al., 1994). Each of the three spectra was normalised such that the spectral fluence equals unity at its maximum value.

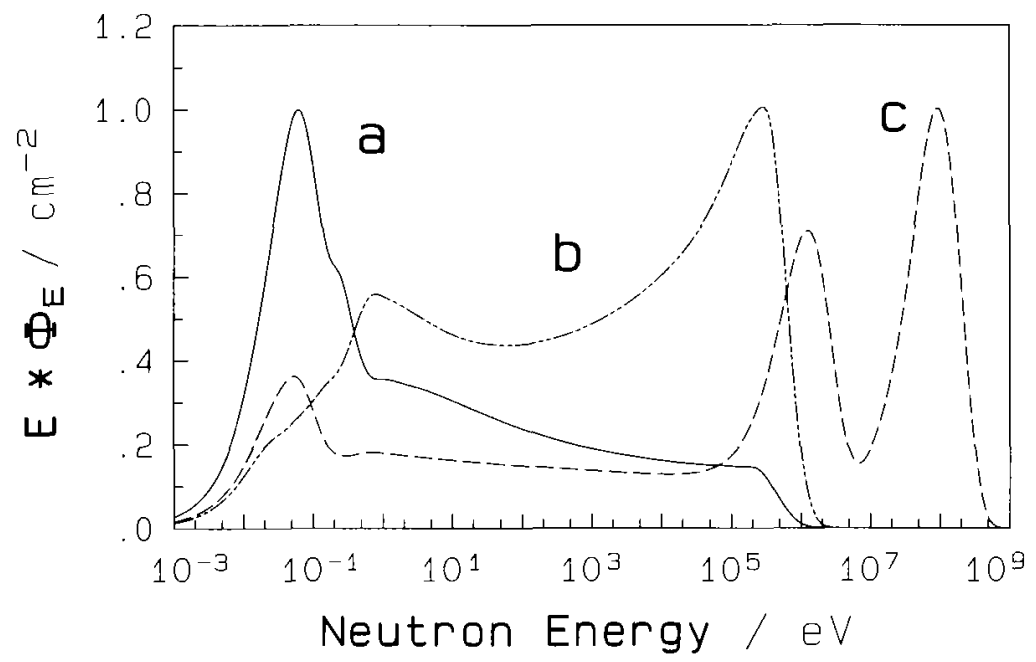

Fig. 1. - Neutron spectra describing two neutron fields at workplaces (a and b) and a high-energy calibration field produced at CERN (c).

Distributions spectrales de la fluence neutronique correspondant à deux champs de rayonnement rencontrés aux postes de travail (a et b) et à un champ d'étalonnages à hautes énergies produit au CERN (c).

It may be that, for a particular application, the neutron energy range is restricted to one or two orders of magnitude, but as concerns radiation protection, the instrumentation used for neutron dosimetry should cover the energies shown in Figure 1.

Most of the survey instruments used in neutron dosimetry (with the exception of the tissue-equivalent proportional counters: TEPC) are based on the following equation describing the dose equivalent (DE) (Schuhmacher et al., 1995; Alberts et al., 1996; Klein, 1997):

$$
H=\int h_{\Phi}(E) \Phi_{\mathrm{E}}(E) \mathrm{d} E
$$

where $H$ is DE, $\Phi_{\mathrm{E}}(E)$ is the spectral neutron fluence of the neutron field considered, and $h_{\Phi}(E)$ is the fluence-to-dose-equivalent conversion factor for neutrons of energy $E$. The reading, $M_{\mathrm{d}}$, of an instrument "d" (TEPCs excepted) in the same 
neutron field is given by a similar relationship:

$$
M_{\mathrm{d}}=\int R_{\mathrm{d}}(E) \Phi_{\mathrm{E}}(E) \mathrm{d} E
$$

where $R_{\mathrm{d}}(E)$ is the fluence response of the instrument "d" to neutrons of energy $E$.

Provided the fluence response has the same energy dependence as the conversion factor, i.e.

$$
R_{\mathrm{d}}(E) \approx h_{\Phi}(E)
$$

the instrument, after being calibrated in a well-known neutron field, is able to indicate correctly the value of the dose equivalent in any neutron field.

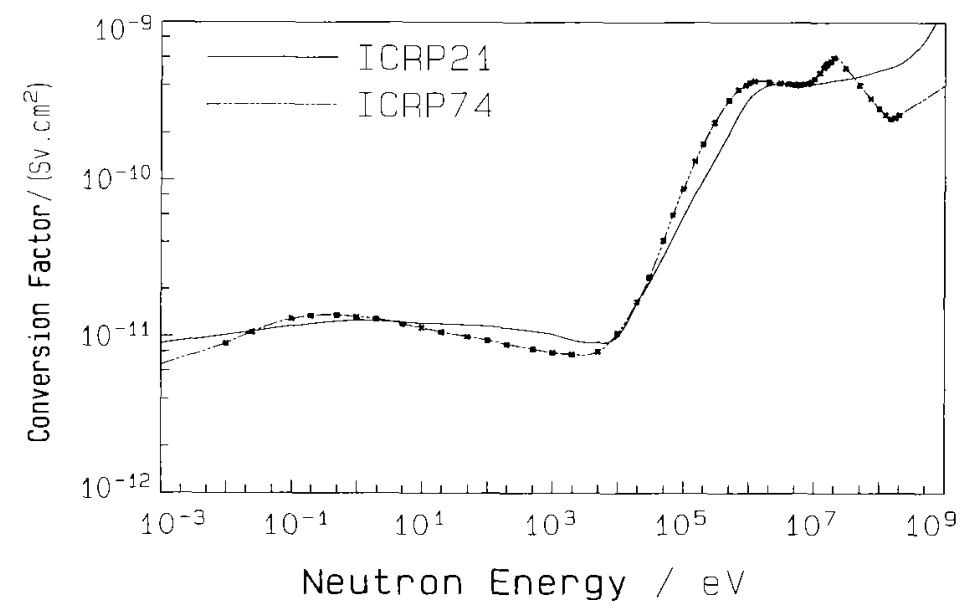

Fig. 2. - Two fluence-to-dose-equivalent conversion functions mostly used at present.

Deux des fonctions de conversion de la fluence en équivalent de dose les plus utilisées aujourd'hui.

Two fluence-to-dose-equivalent conversion factors as a function of energy are shown in Figure 2: conversion to the maximum DE, $H_{\mathrm{MADE}}$, according to the recommendations of ICRP21 (ICRP, 1973) and conversion to the ambient DE, $H^{*}(10)$, following the recommendations of ICRP74 (Siebert and Schuhmacher, 1995; ICRP, 1997).

On account of the very "special" shapes of these conversion functions, none of them can be accurately reproduced by the fluence responses of the existing neutron dosemeters. Most of the instruments encounter difficulties at energies between $100 \mathrm{eV}$ and $100 \mathrm{keV}$, where over- or underestimations by up to a factor of five are 
rather the normal case. At energies higher than $10 \mathrm{MeV}$, large $\mathrm{DE}$ underestimation is generally observed (except for moderator instruments with inner metallic shells).

Taking into account that "real" instrumentation for neutron dosimetry can satisfy equation (3) only approximately, in cases where an accuracy higher than that achievable by these instruments is required one has to return to equation (1) and determine DE via the determination of the spectral neutron fluence $\Phi_{\mathrm{E}}(E)$.

The following chapters give a brief description of some of the instruments and methods used in neutron spectrometry. The description will be restricted to those instruments which use active detectors (i.e. no activation techniques, no TLDs) and have impact on neutron field dosimetry. This also means that these instruments must be portable, or at least transportable. They must cover as wide a neutron energy range as possible, should have an isotropic or nearly isotropic response, and be able to produce reliable results even under extreme environmental conditions as regards temperature (up to $45 \div 50^{\circ} \mathrm{C}$ ), humidity $(25 \%$ to $95 \%$ ), acoustic noise level and electromagnetic interference. The neutron spectrometers should be insensitive to gamma rays, or at least able to distinguish effectively between neutron- and photon-induced events, and maintain their accuracy in intense neutron fields (a few $\mathrm{mSv} / \mathrm{h}$ ) but also under conditions of very low exposure to neutrons (a few nSv/h) (Klein, 1997).

\section{Nuclear data base for neutron spectrometry}

For neutron detection and spectrometry such interactions with matter should be applied, which produce charged particles able to induce in the instrumentation, through ionisation, electrical signals which, if possible, remind in some way of the energy of the detected neutron. The probability (neutron cross section) of the interaction chosen should be high in order to ensure good efficiency of the instrument and good discrimination of parasitic effects. Also, the energy dependence of the cross section should be smooth. When calculated responses of the instrument are used, their accuracy is limited by the uncertainties of the cross sections implied. In Figures 3 and 4 various neutron cross sections are shown as a function of energy, for those interactions which are most frequently used for neutron detection, most of them also in neutron spectrometry.

It should be pointed out that if ${ }^{6} \mathrm{Li}$ or ${ }^{3} \mathrm{He}$ nuclei are involved, the corresponding cross sections continue to increase when the energy decreases below $1 \mathrm{keV}$, following the $1 / \sqrt{E}$ law. This means that at $100 \mathrm{meV}$ they are by a factor of 100 (at $1 \mathrm{meV}$ by a factor of 1000 ) higher than at $1 \mathrm{keV}$, and this makes them suitable for the detection of low-energy (thermal) neutrons. In the very important region from 1 $\mathrm{keV}$ to $20 \mathrm{MeV}$, the n-p scattering cross section not only dominates the others in absolute value, but also is the best known cross section, with an accuracy better than $\pm 0.5 \%$ for the total cross section. 


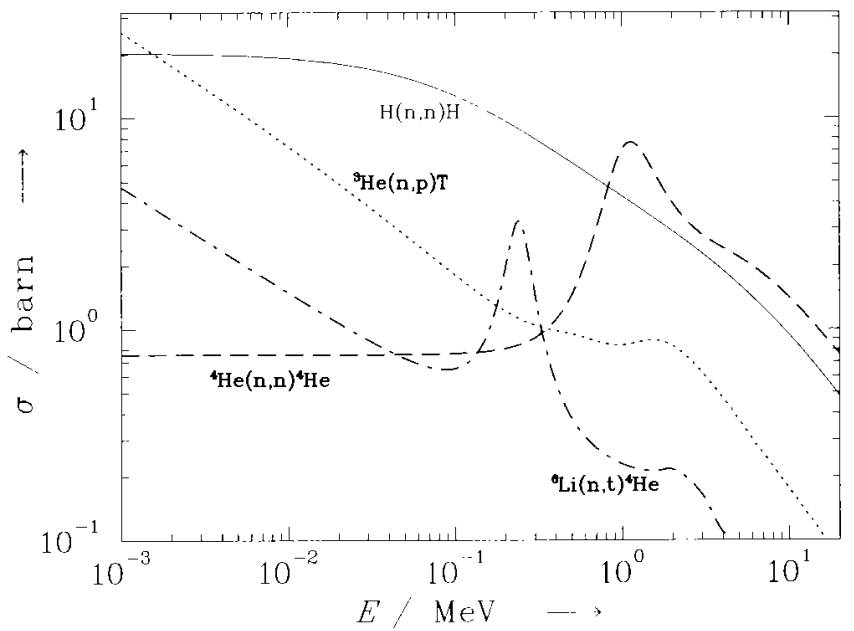

Fig. 3. - Neutron cross sections of a few interactions used in neutron detection and, to some extent, in spectrometry.

Sections efficaces neutroniques de quelques interactions utilisées pour la détection des neutrons et, dans une certaine mesure, en spectrométrie.

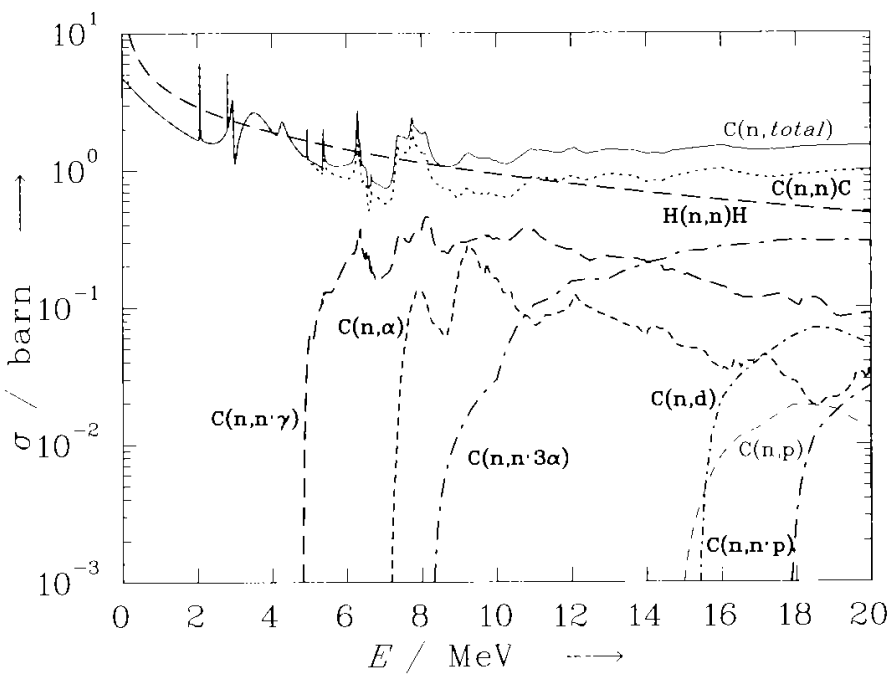

Fig. 4. - Cross sections of various interaction processes of neutrons with carbon nuclei as a function of neutron energy. For comparison, the n-p scattering cross section is also given.

Sections efficaces des différents processus d'interaction des neutrons avec les noyaux de carbone en fonction de l'énergie des neutrons. Pour comparaison, la section efficace de la diffusion n-p est aussi présentée. 
The much more complex interactions of the neutrons with carbon nuclei, for which the cross sections are shown in Figure 4, must be taken into account in instruments using organic (gas, liquid, solid) compounds of hydrogen for neutron detection. Other materials ( $\mathrm{Al}, \mathrm{Cu}, \mathrm{Fe}$, etc.) contained in the detector structure must also be taken into account.

\section{Recoil-proton spectrometry}

Monoenergetic neutrons colliding with hydrogen nuclei produce recoil protons (elastic scattering) whose energy distribution is nearly rectangular (in practice, the finite resolution of the detector smoothes the rectangle, while wall effects, i.e. partial energy deposition in the detector, push some of the proton events towards lower energies), the protons at the upper edge having an energy equal to the energy of the colliding neutrons. In this way the energy of the incident neutrons is memorised in the pulse height spectrum of the recoil protons, provided that the quantity of matter in the detector is large enough to ensure the complete energy dissipation of these protons (edge effects excepted). For the spectrometry of high-energy neutrons of up to $20 \mathrm{MeV}$ or even higher, solid or liquid detectors (Verbinski et al., 1968) (scintillators) are needed; for energies below about $5 \mathrm{MeV}$, gas-filled $\left(\mathrm{H}_{2}, \mathrm{CH}_{4}\right)$ proportional counters are successfully used (Ing et al., 1997); with a ${ }^{4} \mathrm{He}$ gas filling using the n- $\alpha$ scattering (Birch, 1988; Weyrauch et al., 1998), neutron energies up to $15 \mathrm{MeV}$ become accessible.

The pulse-height spectrum of a recoil-proton spectrometer is given by a relationship similar to equation (2):

$$
M(k)=\sum_{i=1}^{n_{\mathrm{E}}} R_{i}(k) \Phi_{E}\left(E_{i}\right) \Delta E_{i}\left(k=1,2, \ldots, n_{\mathrm{c}}\right)
$$

where the integral is replaced by a sum in which the spectral fluence is described by a finite number, $n_{\mathrm{E}}$, of energy groups (bins), the pulse-height spectrum being obtained in $n_{\mathrm{C}}$ channels of a multichannel analyser. The fluence response, $R_{i}(k)$, is the pulse-height spectrum corresponding to the recoil protons produced by neutrons of energy $E_{i}$. Equation (4) can be written also in matrix form:

$$
\mathbf{M}=\underline{\mathbf{R}} \cdot \Phi
$$

in which $\mathbf{M}$ and $\Phi$ are vectors with $n_{\mathrm{C}}$ and $n_{\mathrm{E}}$ components, respectively, and $\underline{\mathbf{R}}$ is the $n_{\mathrm{C}} \cdot n_{\mathrm{E}}$ rectangular response matrix of the spectrometer.

Equation (5) describes a system of $n_{\mathrm{C}}$ linear equations with $n_{\mathrm{E}}$ unknowns. In the case $n_{\mathrm{C}}=n_{\mathrm{E}}$, the solution, $\Phi$, can basically be obtained by simple matrix inversion. In this case the solution is "unique" but some components of the fluence vector may have nonphysical negative values. 
In most cases, an over-determined system of equations, $n_{\mathrm{C}}>n_{\mathrm{E}}$, is used and the solution is obtained by minimising (least-squares method (Perey, 1997; Matzke, 1997; Alevra et al., 1990; Mc Elroy et al., 1967)) the value of chi-squared:

$$
\chi^{2}=(\mathbf{M}-\underline{\mathbf{R}} \cdot \Phi)^{\mathrm{T}} \cdot \underline{\mathbf{C}}^{-1} \cdot(\mathbf{M}-\underline{\mathbf{R}} \cdot \Phi)
$$

where the superscript ${ }^{\mathrm{T}}$ indicates transposition, and $\underline{\mathrm{C}}$ is the covariance matrix of the measured vector $\mathbf{M}$. The solution is obtained as:

$$
\boldsymbol{\Phi}=\left(\underline{\mathbf{R}}^{\mathrm{T}} \cdot \underline{\mathbf{C}}^{-1} \cdot \underline{\mathbf{R}}\right)^{-1} \cdot \underline{\mathbf{R}}^{\mathrm{T}} \cdot \underline{\mathbf{C}}^{-1} \cdot \mathbf{M}
$$

which again may have nonphysical negative values in some energy bins, but nonlinear least-squares procedures (e.g. Mc Elroy et al., 1967) and others which avoid negative spectral fluence values are available (see Matzke, 1997; 1994, and references therein).

It is obvious that the quality of the spectrometer depends, on the one hand, on the quality of the multichannel spectrum, M, i.e. stability of the instrumentation, good separation from noise and photon-induced events, etc., and, on the other hand, on the accuracy of the response matrix, $\underline{\mathbf{R}}$, used, i.e. on the capability of the software (codes and cross-section data) employed to simulate responses in agreement with the experiment, and on the quality of the experiment itself (adequate calibration facilities). Last, but not least, a realistic covariance matrix of the measurements and of the response matrix should be available.

\section{The NE 213 Liquid Scintillation Spectrometer}

A simplified sectional view of a scintillation spectrometer is given in Figure 5. The cylindrical scintillator, covered with a light reflector and protected by an aluminium

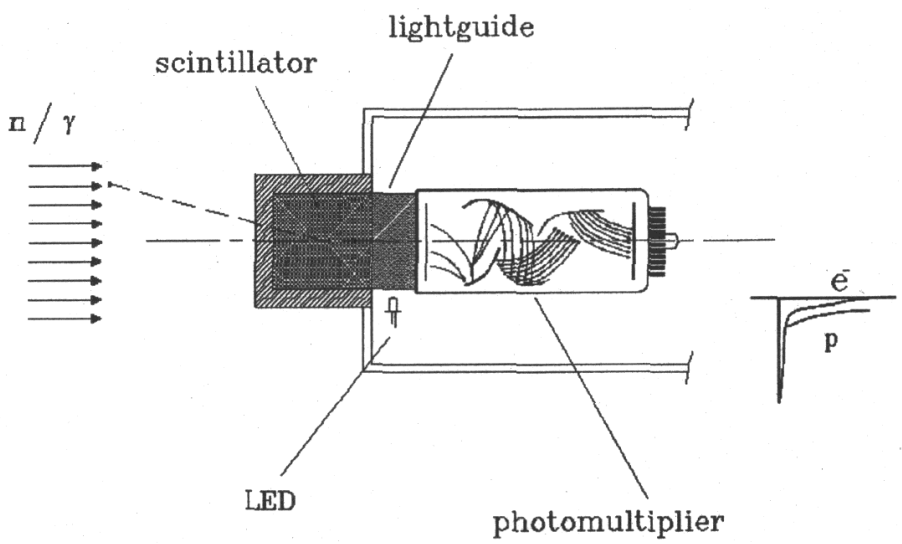

Fig. 5. - Simplified sectional view of a scintillation spectrometer.

Vue simplifiée d'une coupe d'un spectromètre à scintillation. 
case, is coupled to a fast photomultiplier through a light guide. The photomultiplier mounting case ensures an efficient protection against external light and magnetic fields, including the earth's. A light-emitting diode (LED) placed in the light guide produces reference pulses which are stored in a narrow peak above the pulseheight range of the recoil protons and used to stabilise the gain of the whole system (acting on the dynode voltage).
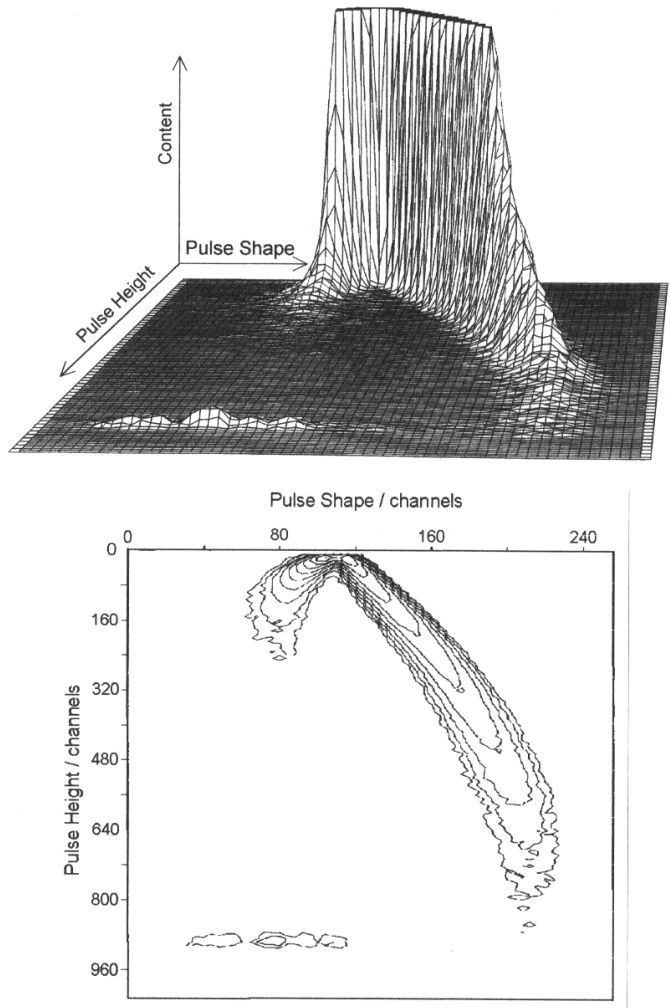

Fig. 6. - Perspective view and contour-line plot of a two-parameter pulse-height distribution registered with an NE 213 scintillation spectrometer in a mixed neutron-photon field. The 10 contour lines extend from $0.005 \%$ to $99 \%$ of the maximum channel content in a geometric sequence. Each line differs from its neighbour by a factor of 3. The perspective view is cut at a level corresponding to the 5th contour line from the bottom.

Vue en trois dimensions et projection en courbes de niveau d'une distribution biparamétrique de l'amplitude des impulsions enregistrée avec un spectromètre à scintillateur NE 213 dans un champ mixte neutron-gamma. Les 10 courbes de niveau vont de $0,005 \%$ à $99 \%$ du contenu maximal des canaux. Chaque courbe differe de sa voisine d'un facteur 3. La vue en trois dimensions est tronquée au niveau de la $5^{e}$ courbe de niveau.

Although composed of small atomic number elements, the scintillator has a quite high sensitivity to photons which induce chiefly Compton electrons. Fortunately, as the electrons' velocities are much higher (and therefore the stopping powers are 
much lower) than those of the recoil protons, the shapes of the light pulses induced by the two kinds of particles are different. This feature is used in an $\mathbf{n}-\boldsymbol{\gamma}$ (i.e. proton-electron) discrimination technique (Adams and White, 1978) which produces for each event a supplementary pulse as a measure for the pulse shape. The scintillation events are submitted to a biparametric analysis, one parameter being the pulse height proportional to the light output, the other the pulse shape. An example of such biparametric (Knauf et al., 1997) spectrum obtained in a mixed neutron-photon field is shown in Figure 6. Pulses induced by neutrons are collected in the left branch of the distribution, those from photons in the right branch. The two kinds of pulses are well separated, except for the region of very low pulse heights.

In order to discriminate between neutron- and photon-induced events, a pulseheight threshold is used, which usually corresponds to recoil proton energies of a few hundreds of keV. When the pulses from each branch are integrated over the pulse shape in each pulse-height channel above the threshold, two separate pulse-height spectra ( $\mathbf{M}$ vectors) are obtained which are induced by neutrons and photons.

The upper part of Figure 7 shows the pulse-height spectrum measured with an NE 213 scintillator $\left(2^{\prime \prime} \times 2^{11} \varnothing\right)$ in a ${ }^{60} \mathrm{Co}$-photon field. The lower plot in this figure shows the gamma spectrum derived using the MIEKE code (Matzke, 1994) for unfolding.

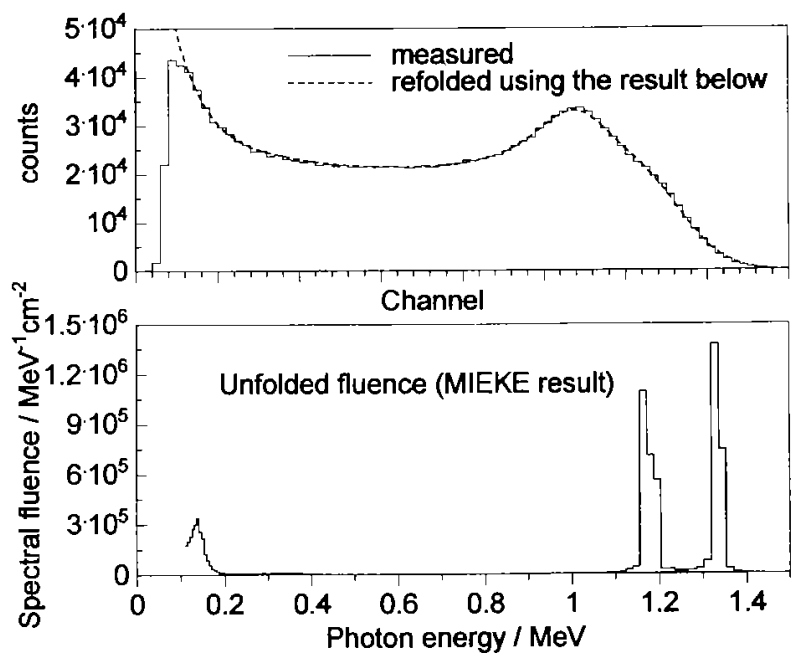

Fig. 7. - The pulse-height spectrum measured with an NE 213 scintillator in a ${ }^{60}$ Co photon field (histogram in the upper plot) and the gamma spectrum (lower plot) derived using the MIEKE code for unfolding. The dotted curve in the upper plot was obtained by folding the obtained gamma spectrum with the calculated gamma response matrix.

Distribution de l'amplitude des impulsions mesurée avec un spectromètre à scintillateur NE 213 dans un champ photonique produit par une source de ${ }^{60}$ Co (histogramme du haut), et spectre de la fluence des photons (figure du bas) obtenu en utilisant le code MIEKE pour la déconvolution. La courbe pointillée sur la figure du haut a été obtenue en convoluant le spectre des photons obtenu avec la matrice de réponse calculée. 
The dotted curve in the upper plot was obtained by folding the obtained gamma spectrum with the calculated gamma response matrix.

Monte Carlo codes are used to calculate the fluence response matrix of the NE 213 scintillator to neutrons (Dietze and Klein, 1982a; Dickens, 1988; Bähr et al., 1998) and to photons (Dietze and Klein, 1982b; Büermann et al., 1993; Novotny, 1997). The validity of these calculated responses is tested by comparison with the experiment. As an example, Figure 8 shows fluence response functions for four neutron energies, calculated with the NRESP code (Dietze and Klein, 1982a) and compared with measured responses (Schmidt and Chenwei, 1997) using monoenergetic neutrons (windows in time-of-flight spectra) of the same energies. Agreement is excellent.
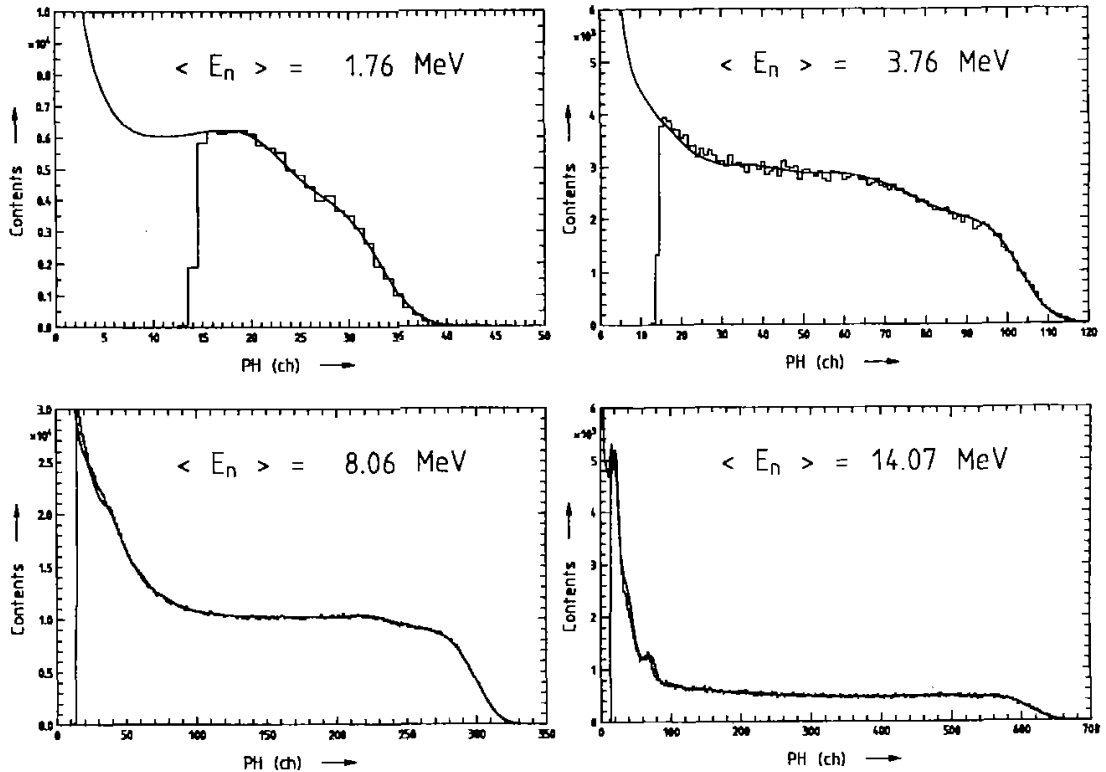

Fig. 8. - Calculated fluence responses of an NE 213 scintillation detector to monoenergetic neutrons of various energies, compared with measurements (Schmidt and Chenwei, 1997).

Comparaison des réponses en terme de fluence d'un détecteur à scintillateur NE 213 calculées et mesurées pour des neutrons monocinétiques de différentes énergies (Schmilt and Chenwei, 1997).

Figure 9 shows pulse-height (middle plots) and time-of-flight (TOF) (upper plots) spectra obtained with an NE 213 scintillation spectrometer for two different neutron sources (Antunes et al., 1986). The neutron fluence spectra (lower plots) were obtained from the scintillation pulse-height spectra using the FERDOR unfolding code (Burrus and Drischler, 1965) (histogram) or derived from the TOF spectra (smooth lines). The spectra presented in the left plot are due to neutrons produced by $11 \mathrm{MeV}$ deuterons in a deuterium gas target. The larger half-width obtained for the "14 MeV" peak (neutrons from the $\mathrm{D}(\mathrm{d}, \mathrm{n})$ reaction) is due to a smoothing procedure applied with FERDOR, in order to prevent oscillations and negative fluence values from 


\section{NEUTRON SPECTROMETRY}

entering in the end result. More recently developed unfolding codes (Matzke, 1994; Tichy, 1988; 1993) may produce a similar half-width as that of the TOF result. The agreement achieved at lower energies where the $D(d, n p)$ neutrons are displayed is remarkable. The agreement in the lower right plot displaying the neutrons induced by $11 \mathrm{MeV}$ deuterons in a thick beryllium target is excellent as well. Even the small peak at about $700 \mathrm{keV}$ could be made evident. This was possible by efficient TOF $\mathbf{n}-\gamma$ discrimination which allowed a detection threshold as low as $300 \mathrm{keV}$.
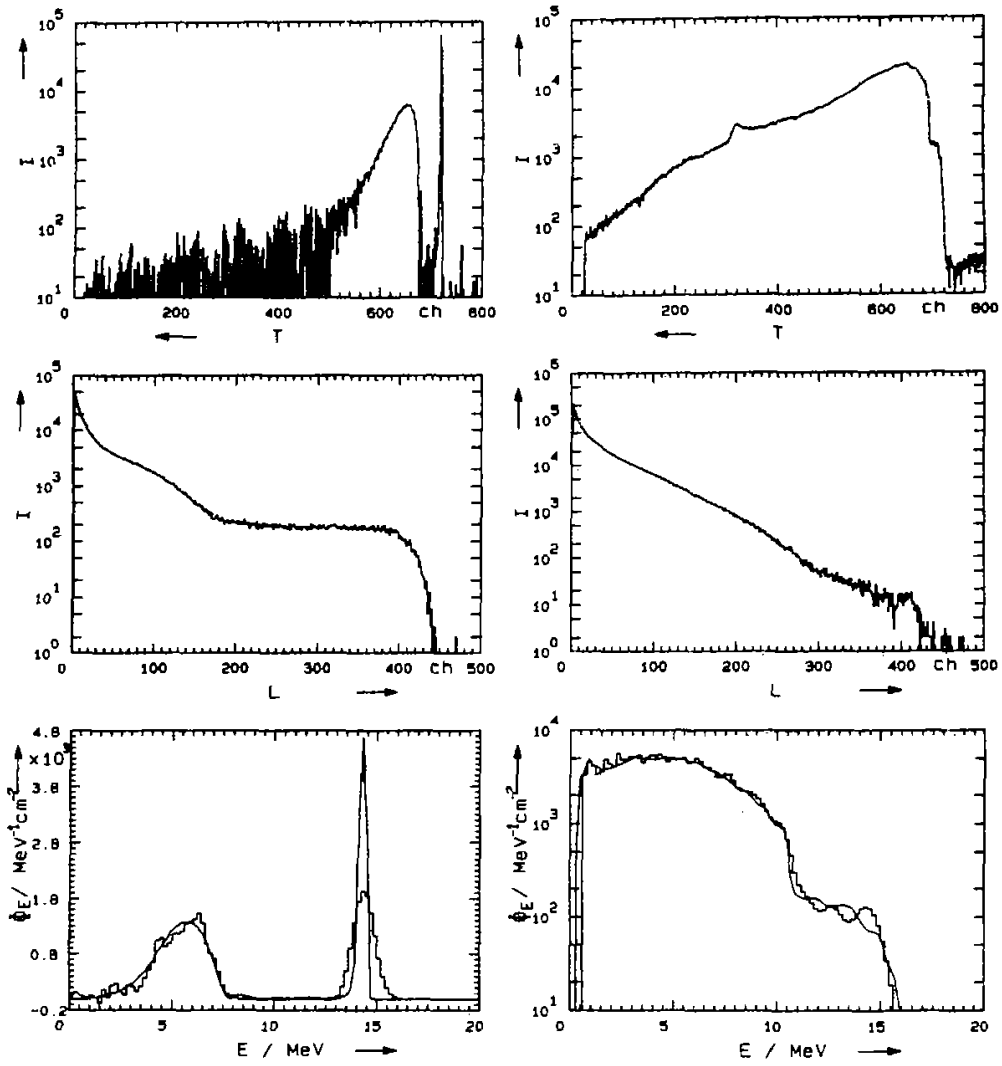

Fig. 9. - Time-of-flight, I(T), (upper plots) and scintillation pulse-height, I(L), (middle plots) spectra measured with an NE 213 scintillation spectrometer, and the neutron fiuence spectra, $\Phi_{E}(E)$, (lower plots) derived from the time-of-flight spectra (smooth line) or obtained by unfolding the pulseheight spectra (histogram). The neutrons were produced by $11 \mathrm{MeV}$ deuterons in a deuterium gas target (Left) or a thick beryllium target (right) (Antunes et al, 1986).

Distributions du temps de vol, $I(T)$, (figures du haut) et de l'amplitude de scintillation, $I(L)$, (figures intermédiaires) mesurées avec un spectromètre à scintillateur NE 213, et distributions spectrales de la fluence de neutrons, $\Phi_{E}(E)$, (figures en bas) déduites des distributions du temps de vol (lignes continues), ou obtenues en déconvoluant les distributions d'amplitude (histogrammes). Les neutrons ont été produits par des deutérons de $11 \mathrm{MeV}$ dans une cible gazeuse de deutérium (figures de gauche), ou dans une cible épaisse de beryllium (figures de droite) (Antunes et al, 1986). 
The accuracy at present achieved in the fluence determination with an NE 213 scintillation spectrometer $\left(\right.$ e.g. $\left.2^{\prime \prime} \times 2^{\prime \prime} \varnothing\right)$ covering the energy range $1 \mathrm{MeV}$ to $20 \mathrm{MeV}$ may be $\pm 3 \%$. The limitation at low energies is due to the necessity to discriminate noise and to avoid the mixture of photon-induced events in the neutron spectrum. The upper limit of $20 \mathrm{MeV}$ is not binding at all. The physical limit depends on the size of the detector (with a scintillator 4" in length (Nolte et al., 1993 ) the $100 \mathrm{MeV}$ limit is exceeded), but for energies exceeding $20 \mathrm{MeV}$ the accuracy of the results suffers sensibly, due to increasing number of open reaction channels and higher uncertainties of the cross section data.

\section{The Spherical Proton-Recoil Proportional Counter (SPRPC)}

Figure 10 shows the sectional view of a spherical proportional counter, namely of the Benjamin or SP2 type (Benjamin et al., 1968), which, through its special anode geometry (design of the wire supports), allows both a sufficiently constant gas multiplication in the whole spherical volume and a nearly isotropic response to be achieved.

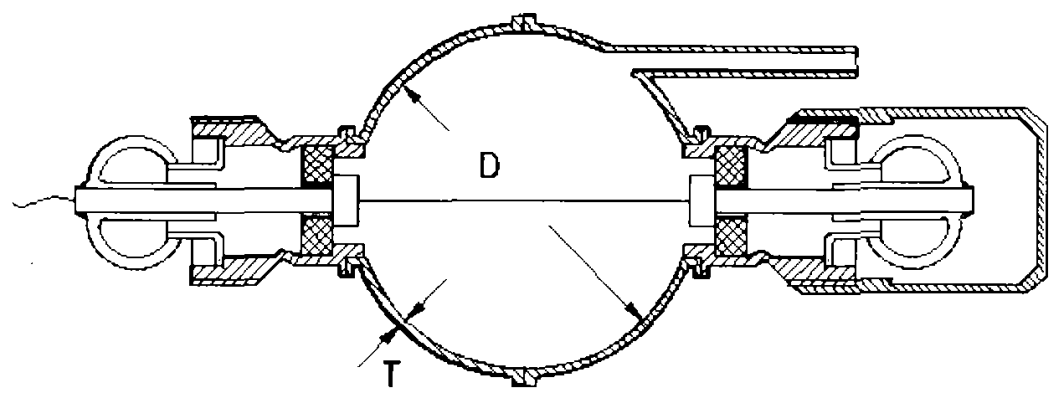

Fig. 10. - Sectional view of an SP2 type spherical proportional counter $(D=40 \mathrm{~mm}, T=0.5 \mathrm{~mm})$.

Vue en coupe d'un compteur proportionnel sphérique de type $S P 2(D=40 \mathrm{~mm}, T=0,5 \mathrm{~mm})$.

Taking into account not only the wall effects but also the remaining nonuniformity of the electric field, the Monte Carlo calculations of the fluence responses of a hydrogen-filled PC produce a fluence response matrix in good agreement with the experiment (Weise et al., 1991; Knauf et al., 1998).

The use of various gas fillings $\left(\mathrm{H}_{2}\right.$ or $\mathrm{CH}_{4}$ or mixtures with other gases) at various pressures (also in counters of different diameters), and, in addition, the modification of the gas multiplication (through the high-voltage supply) or the gain of the electronics allow various energy bands to be covered in the measurements (Ing et al., 1997; Knauf et al., 1997). Usually the SPRPCs are operated such that all neighbouring bands partly overlap and altogether cover the energy range from about $50 \mathrm{keV}$ to about 2 (5) MeV (ensuring in this way also overlap with the NE 213 energy range). If $\mathbf{n}-\gamma$ discrimination is applied (Bennet, 1962), the accessible energy range can be extended to lower energies of at least $10 \mathrm{keV}$.

An example of a neutron spectrum obtained with a $\mathrm{CH}_{4}$-filled SPRPC measuring iron-filtered neutrons (Knauf et al., 1997) is shown in the upper part of Figure 11. 


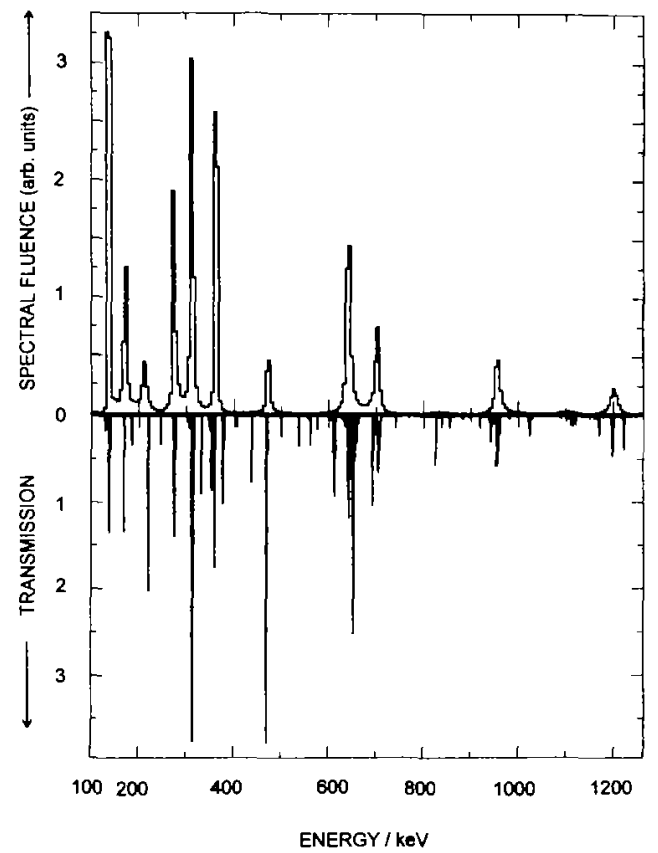

Fig. 11. - Spectral neutron fluence unfolded from an SPRPC measurement of iron-filtered reactor neutrons. The lower plot shows the calculated transmission function of the iron filter (Knauf et al., 1997).

Distribution spectrale de la fluence neutronique déconvoluée à partir des mesures faites en exposant un compteur proportionnel sphérique à protons de recul, à des neutrons produits par un réacteur nucléaire et ayant traversé un filtre de fer. La partie inférieure de la figure présente le résultat du calcul de la fonction de transmission du filtre de fer.

For comparison, the calculated transmission function of the iron filter $(672 \mathrm{~mm}$ long) is plotted in the lower part of the figure.

Another example is given in Figure 12, presenting results of measurements performed in the vicinity of a mockup of a transport cask filled axially with ${ }^{252} \mathrm{Cf}$ sources instead of spent nuclear fuel (Knauf et al., 1997). The full-line histogram includes four different measurements unfolded by means of the UNFANA code (Weise, 1995): 1) the energy range above $1 \mathrm{MeV}$, well covered by the scintillation spectrometer with n- $\gamma$ discrimination (simultaneously, the photon spectrum from about $250 \mathrm{keV}$ to $8 \mathrm{MeV}$ could be determined); 2) the segment from $100 \mathrm{keV}$ to $1350 \mathrm{keV}$ where a $\mathrm{CH}_{4}$-filled counter $(275 \mathrm{kPa})$ is used without $\mathbf{n}-\gamma$ discrimination; in the energy segments $\mathbf{3}$ ) (from $50 \mathrm{keV}$ to $450 \mathrm{keV}$ ) and 4) (from $10 \mathrm{keV}$ to $100 \mathrm{keV}$ ) the $\mathrm{H}_{2}$-filled counter ( $196 \mathrm{kPa}$, $98 \% \mathrm{H}_{2}$ and $2 \% \mathrm{CH}_{4}$ as quenching gas) is used, but in segment 4 both higher gas amplification and $\mathbf{n}-\gamma$ discrimination are used. The arrows indicate the energies at which the results obtained in the four mentioned segments have merged. The dotted histogram in Figure 12 is the result of MCNP calculations (Bernatt et al., 1995) for exactly the same geometry as used in the measurements. 


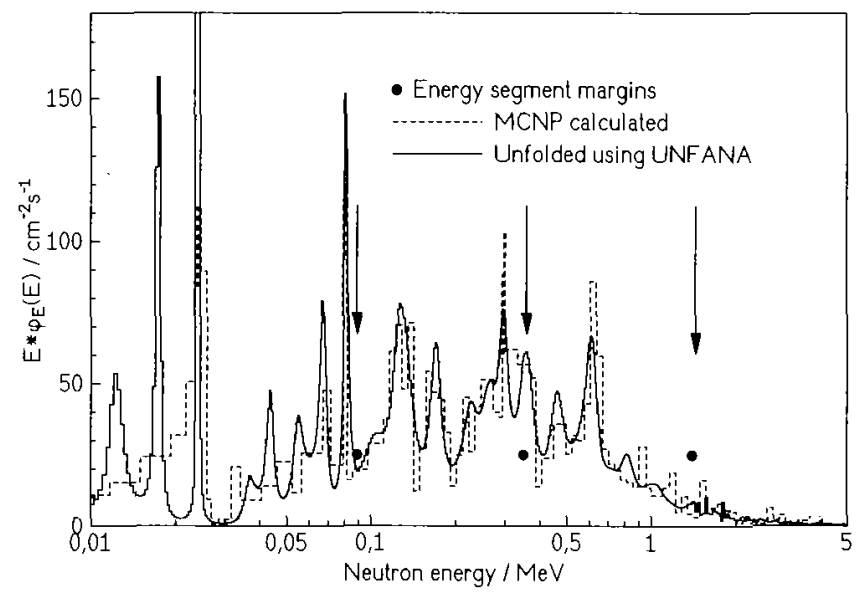

Fig. 12. - The spectral neutron fluence rate (in lethargy representation) obtained with recoil-proton spectrometry in the vicinity of a mockup of a transport cask filled axially with ${ }^{252} \mathrm{Cf}$ sources. The dotted histogram shows the MCNP calculated spectrum (Bernatt et al., 1995).

Débit de fluence spectrale des neutrons (représentation en "léthargie") obtenu en utilisant la spectrométrie à protons de recul près d'un modèle réduit d'un container de transport rempli le long de son axe avec des sources de ${ }^{252} \mathrm{Cf}$. L'histogramme en pointillé représente le spectre calculé avec MCNP (Bernatt et al., 1995).

It should be borne in mind that the pulse-height spectrum in a segment has to be corrected for pulses caused by neutrons in the regions above, an effect referred to in the literature as downscattering. For this reason the data analysis is carried out topdown, i.e. the measurement in a higher region is evaluated prior to that in the adjacent lower region. This also means that recoil-proton spectrometry cannot produce reliable results in a limited energy range if neutrons of higher energies are present in the field under investigation and their spectral fluence is not sufficiently well known.

The accuracy attained in the fluence determination with SPRPC spectrometers is about $\pm 5 \%$ (Weyrauch and Knauf, 1992), but recent developments give rise to the hope that, at least under favourable experimental conditions, one could come close to a performance of $\pm 3 \%$.

\section{Spectrometry with a ${ }^{3} \mathrm{He}$-filled proportional counter}

This kind of spectrometer employs for neutron detection the reaction

$$
{ }^{3} \mathrm{He}+\mathrm{n} \rightarrow \mathrm{p}+\mathrm{T}+764 \mathrm{keV}
$$

in which the entire energy of the neutron is preserved in the sum of the kinetic energies of the resulting charged particles, i.e. proton and triton. If the size of the counter is large enough and the ${ }^{3} \mathrm{He}$ pressure also (a few hundreds of $\mathrm{kPa}$ ), both proton and 
triton dissipate their whole energy in the counter gas (i.e. the contribution of wall effects is low), producing for monoenergetic incident neutrons of energy $E_{\mathrm{n}}$ a full-energy peak in the resulting pulse-height spectrum, which corresponds to an energy $E_{\mathrm{n}}+764 \mathrm{keV}$. Thermal neutrons, for which the reaction concerned has a very high cross section (a few thousands of barn), produce a peak corresponding to an energy of $764 \mathrm{keV}$ and a half width of about $20 \mathrm{keV}$. With such a resolution in pulse-height, peaks due to monoenergetic neutrons with energies above $25 \mathrm{keV}$ can be distinguished from the thermal peak, provided that the contribution of the thermal neutrons in the pulse-height spectrum is not dominant. In order to reduce drastically the influence of the thermal neutrons, the counter is shielded with cadmium. Even with such precautions, in many neutron fields encountered the contribution of the epithermal neutrons, for which the reaction cross section is still very high, is dominant in the pulse-height spectrum, making the extraction of reliable spectrometric information impossible. Otherwise, under favourable conditions, the energy range from 50 (25) $\mathrm{keV}$ to about $2 \mathrm{MeV}$ can be analysed. Such favourable conditions were met at the iron filter installed at the PTB reactor. Figure 13 shows the pulse-height spectrum (broad peaks), in energy units, above the thermal peak (i.e. the given abscissa values correspond to the peak energy minus $764 \mathrm{keV}$ ) and the unfolded energy spectrum (narrow peaks) (Matzke, 1997). The unfolding takes into account the response of the counter as a function of energy, i.e. the dependence on neutron energy of the reaction cross section and of the counter resolution. In the lower part of the Figure 13, the calculated transmission function of the iron filter is again given for comparison.

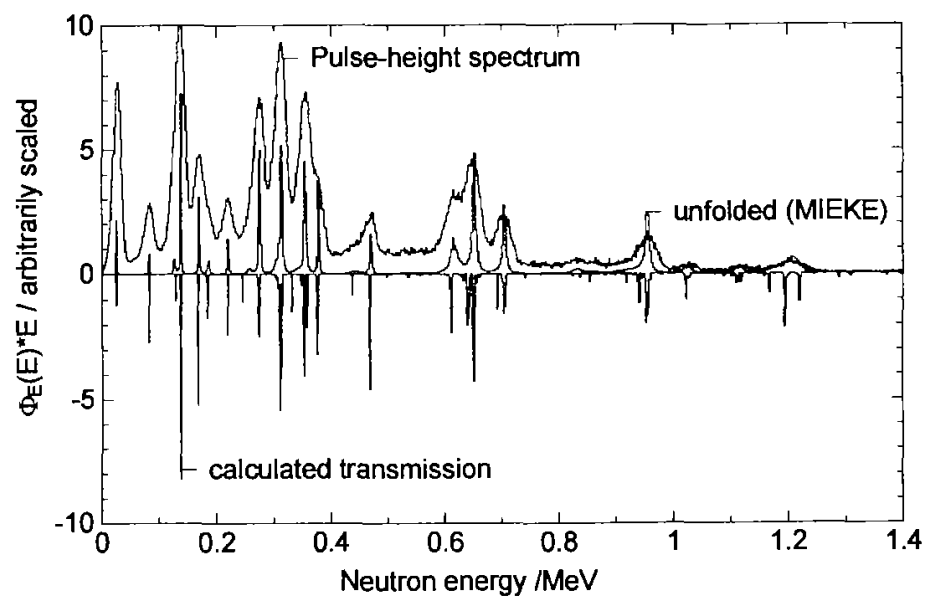

Fig. 13. - The pulse-height spectrum (broad peaks) and the unfolded spectrum (narrow peaks) obtained with $a^{3}$ He-filled proportional counter at the iron filter of the PTB reactor, compared with the calculated transmission of the iron filter (lower plot) (Matzke, 1997).

Distribution de l'amplitude des impulsions (pics larges) et spectre déconvolué (pics étroits), obtenues avec un compteur proportionnel rempli $d^{, 3} \mathrm{He}$ placé à proximité du filtre de fer du réacteur du PTB. Comparaison avec le résultat du calcul de la fonction de transmission du filtre de fer (partie inférieure de la figure) (Matzke, 1997). 


\section{The Bonner sphere (multisphere) spectrometer (BSS)}

Detectors containing ${ }^{6} \mathrm{Li},{ }^{10} \mathrm{~B}$ or ${ }^{3} \mathrm{He}$ have a very high efficiency (up to $100 \%$ ) for the detection of thermal neutrons. In order to make them sensitive to higher-energy neutrons, they are usually covered by some moderator rich in hydrogen nuclei. This procedure is nearly as old as the neutron physics, and in the year 1960 the use of spherical polyethylene moderators $\left(\mathrm{PE},\left(\mathrm{C}_{2} \mathrm{H}_{4}\right)_{n}\right)$ of various sizes was proposed (Bramblett et al., 1960) in order to extract spectrometric information from measurements performed with such instruments.

Originally, the thermal neutron-sensitive detector (central detector, $\mathrm{CD}$ ) used was a small ${ }^{6} \mathrm{LiI}$ scintillator which is still in use in various laboratories. This $\mathrm{CD}$ has the disadvantage to be quite sensitive to photons on account of its high mass density and high concentration in iodine, an element with high atomic number. At the beginning of the seventies, French researchers (Bricka et al., 1973; Bruxerolle, 1971; Caizergues and Poulot, 1972; Mourgues, 1975; 1984; Zaborowski, 1981) replaced the ${ }^{6} \mathrm{LiI}$ scintillator by a small ${ }^{3} \mathrm{He}$-filled proportional counter which is much less sensitive to photons but has a quite low gas amplification, with consequences for the discrimination of noise. Distinct improvement in this measurement technique has been achieved by use of a spherical (32 mm diameter) ${ }^{3} \mathrm{He}$-filled (usually $200 \mathrm{kPa}$ ) proportional counter of type SP9 (Centronic Ltd., UK) (Thomas P.M. et al., 1984; Alevra et al., 1992a; Thomas D.J. et al., 1994; Thomas D.J., 1992; Wiegel et al., 1994).

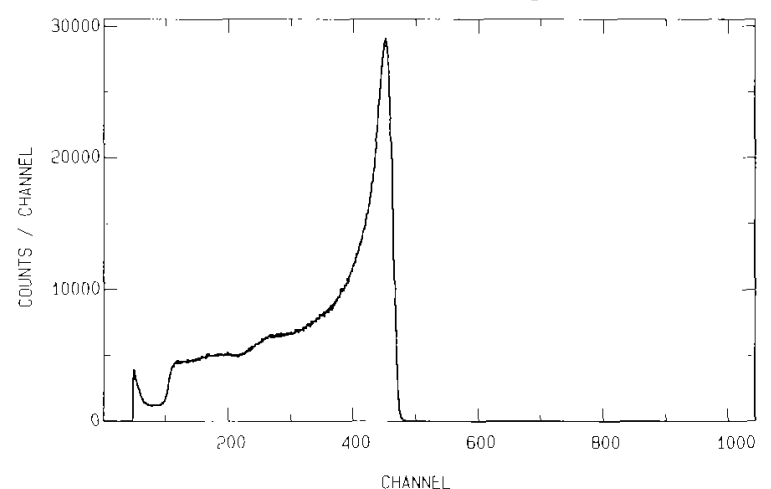

Fig. 14. - Pulse-height spectrum obtained using an SP9 counter in a mixed neutron-photon field.

Distribution de l'amplitude des impulsions obtenue avec un compteur SP9 dans un champ mixte neutron-gamma.

The advantages of such a detector can be seen in Figure 14 which shows a pulseheight spectrum obtained in a mixed neutron-photon field. The full-energy peak, corresponding to an energy of $764 \mathrm{keV}$ (see Eq. (8)), is followed by a pulse-height distribution in lower channels due to wall effects which are considerable in such a small counter. Nevertheless, the lowest pulse height induced by a neutron corresponds to a quarter of the full energy (the proton fully escaped, the triton fully inside), which is high enough to allow an efficient discrimination of the neutron events from noise and photon-induced pulses. 


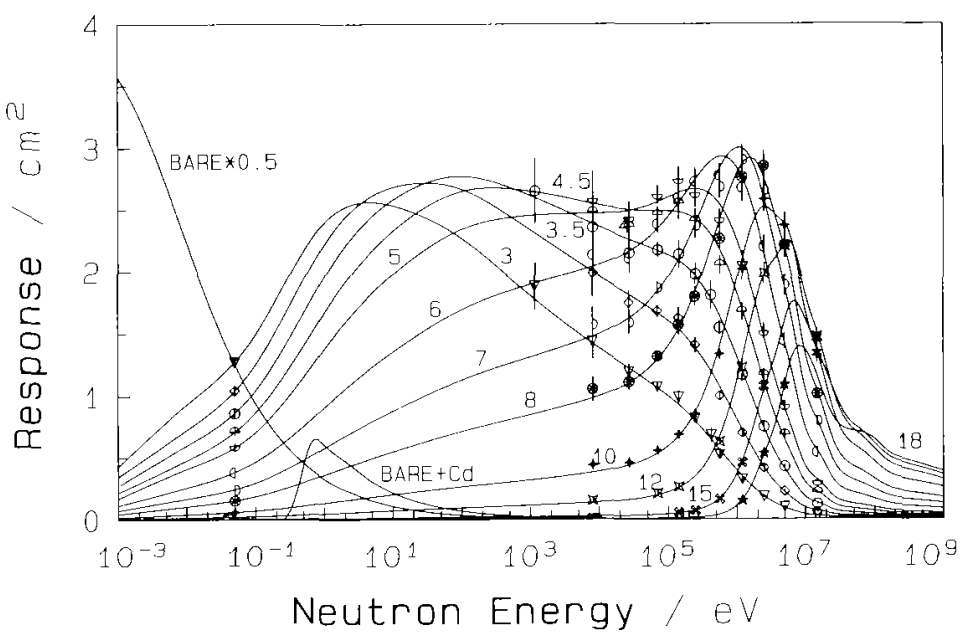

Fig. 15. - The fluence response matrix of the PTB " $C$ " Bonner sphere spectrometer.

La matrice de réponse en fluence du spectromètre à sphères de Bonner (SSB) PTB "C".

Figure 15 presents the fluence response matrix (see Eqs. (2) and (4-7)) of the PTB "C" Bonner sphere spectrometer. For neutron energies from $1 \mathrm{meV}$ to $20 \mathrm{MeV}$, this matrix is based on experimental data obtained at various energies (see the experimental points and their uncertainties) (Alevra et al., 1992; Thomas D.J. et al., 1994) and calculated responses (Thomas D.J. et al., 1992; Wiegel et al., 1994) which were adjusted to fit the experimental data. For energies between $20 \mathrm{MeV}$ and about $300 \mathrm{MeV}$, experimental data for $55 \mathrm{MeV}$ quasi-monoenergetic neutrons (Alevra and Schrewe, 1997) were combined with calculated responses (Aroua et al., 1992). Finally, the data were supplemented up to $1 \mathrm{GeV}$ using empirical extrapolations.

The PTB BSS consists of 14 detectors, i.e. the SP9 counter used "bare" or under a cadmium shielding, or placed at the centre of 12 polyethylene spheres with diameters ranging from $7.62 \mathrm{~cm}(3 ")$ to $45.72 \mathrm{~cm} \mathrm{(18").} \mathrm{From} \mathrm{measurements} \mathrm{with} \mathrm{this}$ detector system in a certain neutron field, up to 14 count rates can be obtained (Eq. (2)), which can be used to solve equation (5) and to find the spectral neutron fluence $\Phi$ (Eq. (7)). Figure 16 shows the components of the vectors $\mathbf{M}$ (readings of spheres with different diameters) obtained in neutron fields whose neutron spectra are given in Figure 1.

The spectrum a, rich in thermal neutrons, produces high count rates in the bare counter (diameter: 0 ) and in the smallest spheres. In contrast to this, the spectrum c, rich in high-energy neutrons, induces high count rates in the large spheres. The smoothness of the curves in Figure 16 indicates stable measurements, with small uncertainties (statistical or of another kind). 


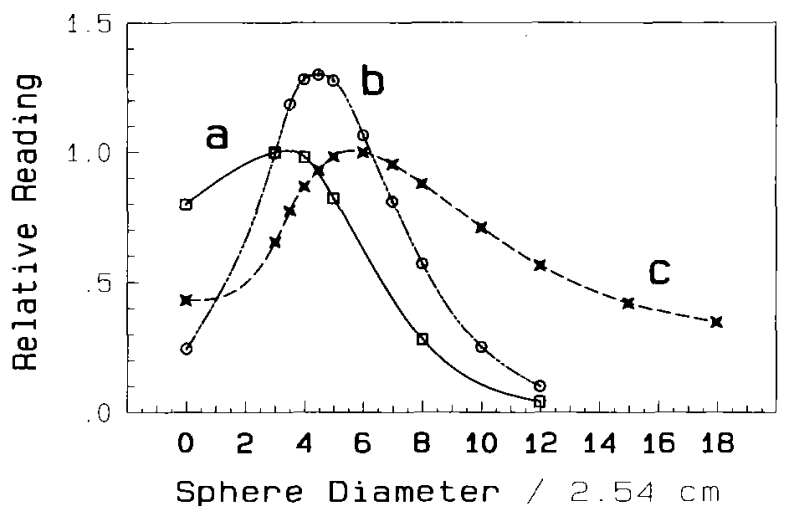

Fig. 16. - The relative readings of the BSS in three neutron fields whose neutron spectra are shown in Figure 1.

Comptages normalisés du SSB obtenus dans les trois champs neutroniques dont les spectres sont présentés sur la Figure 1.

Solving equation (5), in spite of the reduced number of components of the vector $\mathbf{M}$ (few-channel unfolding), one looks for a solution, $\Phi$, described by a rather large number of energy groups. In this case the system of linear equations described by equation (5) is underdetermined, and the solution is not unique. Due to the fact that responses of spheres of similar diameter have quite similar shapes (the corresponding equations in the system are not truly linear independent), the amount of details (number of parameters) which can be used to describe a spectrum is rather small (3 using 4 spheres, 4 using 8 spheres, as indicated in reference Alevra et al., 1992b). When the number of spheres in the system is increased (for example to 14), the situation will not improve substantially. The information obtained from measurements is in this case redundant, but the redundancy can be useful in some problematic measurements. In order to chose, from a multitude of possibilities, a solution which is not only statistically compatible with the measured rates but also physically meaningful, the careful selection of a priori information (e.g.guess spectra) is recommended.

The check of the solution spectrum for compatibility with the measurements is mandatory. An example of such a check is given in Figure 17. When the solution spectrum is folded with the fluence response matrix (Eqs. (2) or (5)), the calculated readings, $\mathbf{C}_{\mathrm{d}}$, are obtained, and in addition, the ratios $\mathbf{r}_{\mathrm{d}}=\mathbf{M}_{\mathrm{d}} / \mathbf{C}_{\mathrm{d}}$, where $\mathbf{M}_{\mathrm{d}}$ are the measured readings. The deviations of the $\mathbf{r}_{d}$ values from unity should be comparable with their uncertainties, resulting in a reduced chi-squared value near unity.

Although the poor energy resolution of the BSS does not allow a detailed description of the spectral fluence to be given, a well-characterised set of spheres allows the integral neutron fluence to be determined (Alevra, 1994) within $\pm 4 \%$, and, due to some freedom in describing the spectral shape, the neutron dose equivalent within $\pm 15 \%$ or even better (Alevra et al., 1997). For illustration, an exercise presented in reference (Alevra et al., 1997) is reproduced here. The exercise uses the BS readings 


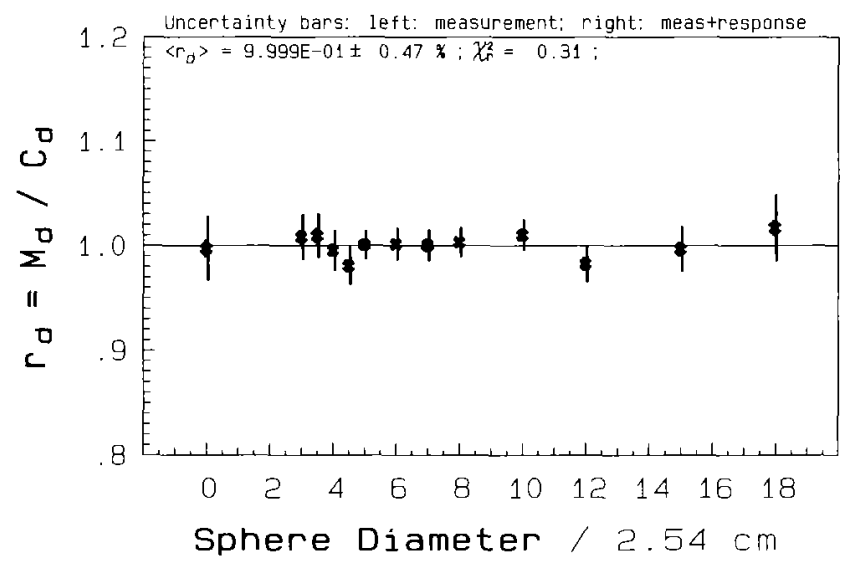

Fig. 17. - The ratios $\left(r_{d}\right)$ of measured $\left(M_{d}\right)$ to calculated $\left(C_{d}\right)$ readings of the detectors used to measure the spectrum $c$ from figure 1 .

Les rapports $\left(r_{d}\right)$ entre les valeurs mesurées $\left(M_{d}\right)$ et calculées $\left(C_{d}\right)$ des comptages des détecteurs utilisés afin de mesurer le spectre c de la figure 1.

obtained with good accuracy in a neutron field at the Czech nuclear power plant in Dukovany. The solution space was checked by generating a large number (22627) of reasonable spectra which uniformly fill a space where also valid solutions could be found. 188 spectra satisfying the chi-squared criterion

$$
\left|1-\chi_{\mathrm{r}}^{2}\right| \leq \sqrt{\frac{2}{n_{\mathrm{D}}-1}}
$$

where $\chi_{\mathrm{r}}^{2}=\chi^{2} /\left(\mathbf{n}_{\mathrm{D}}-1\right)$ is the reduced chi-squared and $\mathbf{n}_{\mathrm{D}}$ is the number of detectors/spheres used in measurement, were retained as valid. The frequency distributions of the integral fluence and dose-equivalent values deduced from these solutions are shown in Figure 18.

The frequency analysis was made in 41 channels of $1 \%$ width, covering the relative deviations from $-20.5 \%$ to $+20.5 \%$ with respect to the solution adopted as the best one (lowest chi-squared). When the frequency distributions obtained are approximated with Gaussians, the resulting standard deviations are $\pm 0.9 \%$ for the fluence and $\pm 4 \%$ for the dose equivalent, in which the uncertainties of the measured count rates and of the individual fluence responses (uncorrelated) have been considered. Adding quadratically the correlated uncertainty of the whole response matrix, estimated at $\pm 3 \%$, uncertainties of $\pm 3.1 \%$ for the integral fluence and \pm 5 for the dose equivalent are obtained.

Details of spectral distribution can be obtained on the basis of adequate a priori information (taken from calculations or measurements with higher energy resolution), but even in cases where no a priori information is available, skilful unfolding will produce a solution which, although smoothing the details, will reproduce quite well 


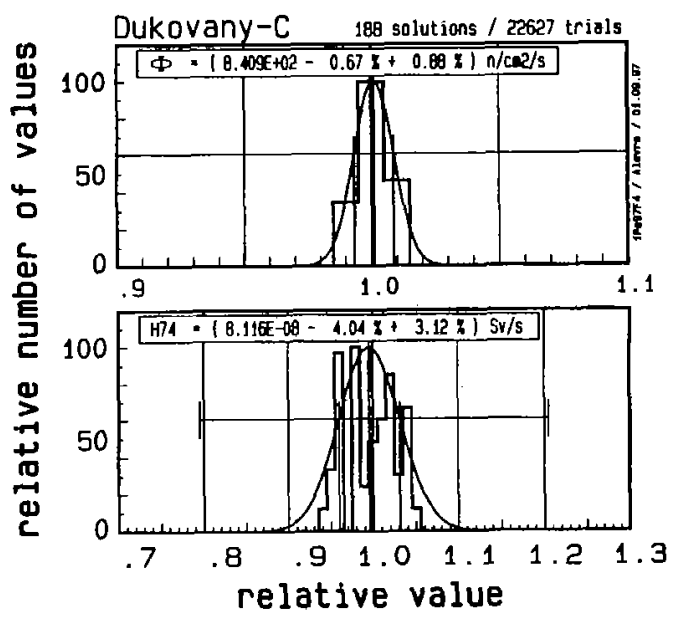

Fig. I8. - The "frequency" distributions of the integral fluence and dose-equivalent values due to "all" valid solutions, relative to the values of the "best" solution.

Distributions de la "fréquence" des valeurs intégrales de la fluence et de l'équivalent de dose dues à "toutes" les solutions valables, normalisées par rapport aux valeurs de la "meilleure" solution.

the general shape of the neutron spectrum. As examples, Figure 19 shows two sets of solution spectra obtained from measurements in a point at $2 \mathrm{~m}$ distance from the lid of a mockup of a transport cask filled axially with ${ }^{252} \mathrm{Cf}$ sources (Alevra et al., 1995). The measurements were performed in two places, free in air above ground, and in a salt mine.

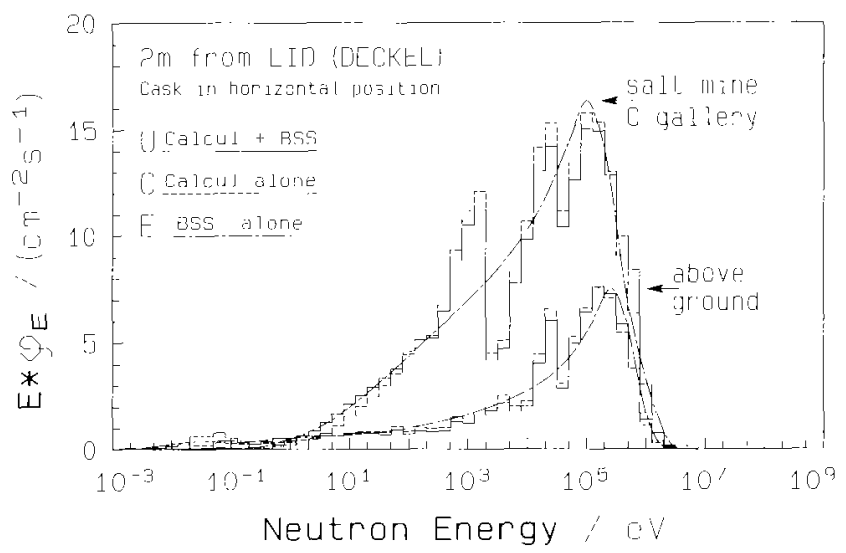

Fig. 19. - Two neutron spectra measured with the BSS in the vicinity of a mockup of a transport cask filled axially with ${ }^{252} \mathrm{C} f$ sources. For details see text.

Deux spectres de neutrons mesurés avec le SSB près d'un modèle réduit d'un container de transport rempli le long de son axe avec des sources de ${ }^{252} \mathrm{Cf}$. Voir texte pour les détails. 
The smooth dot-dashed spectra were obtained from the BS readings without using any a priori information, but trying a large variety of guess spectra. The thin histograms follow from Monte Carlo calculations (Bernatt et al., 1995; Bernatt and Mattes, 1995) for the same geometries as used in measurements. The thick histograms resulted from the unfolding of the BS readings using the calculated spectra as a priori information. The agreement between the three variants of solution is satisfactory in shape and excellent in integral results. In this series of measurements, the good agreement between BSS results and calculations is fully supported by measurements with SPRPCs (see Fig. 12).

It is interesting to compare results obtained with various types of neutron spectrometers. Only a few examples will be given here. Figure 20 presents results of measurements carried out in a repository for $\mathrm{PuO}_{2}$ samples (Knauf et al., 1989). A detailed description of the neutron spectral fluence is obtained with SPRPCc in the energy interval from $50 \mathrm{keV}$ to $1.2 \mathrm{MeV}$ and with a scintillation spectrometer for energies above $1.2 \mathrm{MeV}$. The smooth neutron spectrum obtained with the BSS, independently from the other two results, is in good agreement with them and completes the information on the investigated field for all energies down to the thermal region.

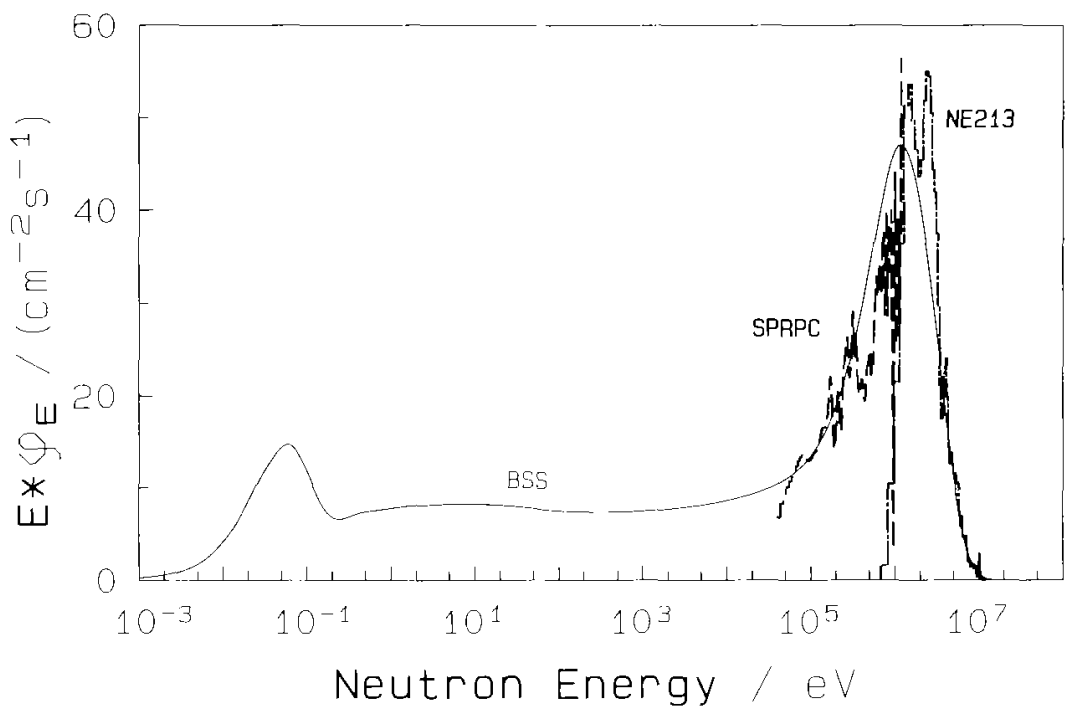

Fig. 20. - The neutron spectral fluence rate obtained with a BSS in a repository for $\mathrm{PuO}$, compared with high-resolution proton recoil results.

Le débit de fluence spectrale des neutrons obtenu avec un SSB dans une casemate de stockage de $\mathrm{PuO}_{2}$, comparé avec résultats obtenus avec les techniques à protons de recul présentant une haute résolution. 


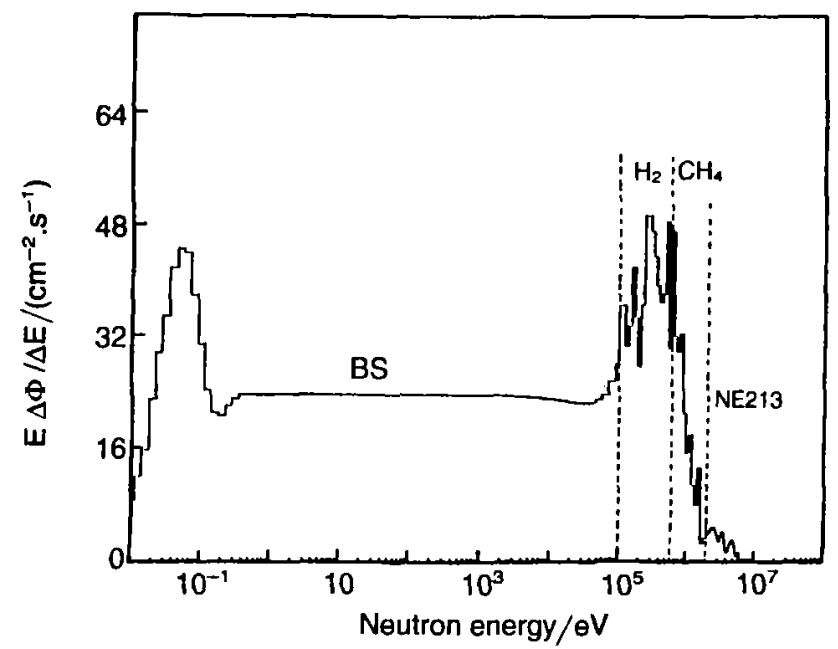

Fig. 21. - The neutron spectral fluence rate of a realistic calibration field obtained at CEN Cadarache (IPSN) using three different neutron spectrometry techniques (Figure taken from Chartier and Posny, 1995).

Débit de fluence spectrale des neutrons mesuré dans un champ neutronique réaliste, utilisé pour l'étalonnage des dosimètres, obtenu au CEN Cadarache (IPSN) en mettant en auvre trois techniques spectrométriques différentes (Figure issue de Chartier and Posny, 1995).

A neutron spectrum obtained by combining results from proton-recoil spectrometry and BS spectrometry is shown in Figure 21. This spectrum is a CEA-France result (Chartier and Posny, 1995) describing one of the realistic neutron calibration fields produced at CEN Cadarache (Chartier et al., 1992). The BS result alone (not shown here) covers the whole energy range of interest and is in full agreement with proton-recoil spectometry.

In an international intercomparison organised at CEN Cadarache, which offered another realistic neutron calibration field, nine European laboratories took part with BSSs. In Figure 22 the corresponding nine proposed neutron spectra are compared (Thomas et al., 1997) with MCNP calculations. Most of the participating laboratories presented results which were in good agreement with one another and with the calculation.

An important feature of the BSS, at least when an SP9 counter is used as CD and the neutron events can be clearly distinguished from the parasitic ones, is the capability to perform reliable measurements in neutron fields with very low fluence rates (e.g. the neutron natural background induced by the cosmic radiation at ground level, or even inside buildings with thick concrete shieldings). In order to estimate the limits in low-level measurements, the instrumental background (i.e. the count rates in the absence of neutrons) was measured in the "Asse" salt mine at a depth of $850 \mathrm{~m}$ below the earth's surface (Aleva et al., 1997; Krauf and Wittstock, 1997). 


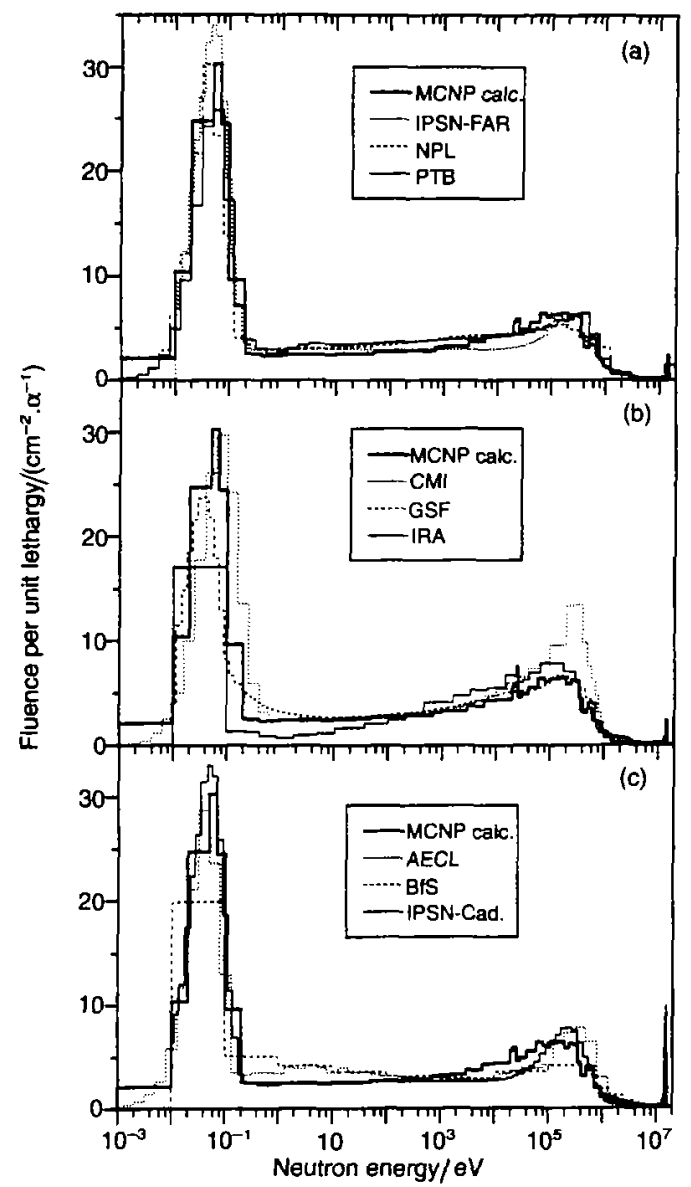

Fig. 22. - Comparison of the spectral results, as originally submitted by the participants in the Cadarache intercomparison, with one another and with the MCNP calculation (Fig. I in Thomas D.J. et al., 1997).

Distributions spectrales de la fluence mesurées par les participants à l'intercomparaison de Cadarache. Comparaison avec les résultats du calcul MCNP (Fig. I dans Thomas et al., 1997).

Figure 23 shows pulse-height spectra obtained with two SP9 counters (named "A" and "D") placed inside BSs. The two spectra were collected during $19760 \mathrm{~min}$ and $38000 \mathrm{~min}$, respectively, which explains, taking into account the adverse environmental conditions, the huge contribution of parasitic pulses. Nevertheless, the fullenergy peak due to neutrons, which should be located at about channel 420 , does not appear at all. The white pulse-height distributions which are seen above channel 300 do not contain any parasitic contribution and describe the instrumental background due only to the SP9 counters (without electronic noise). 


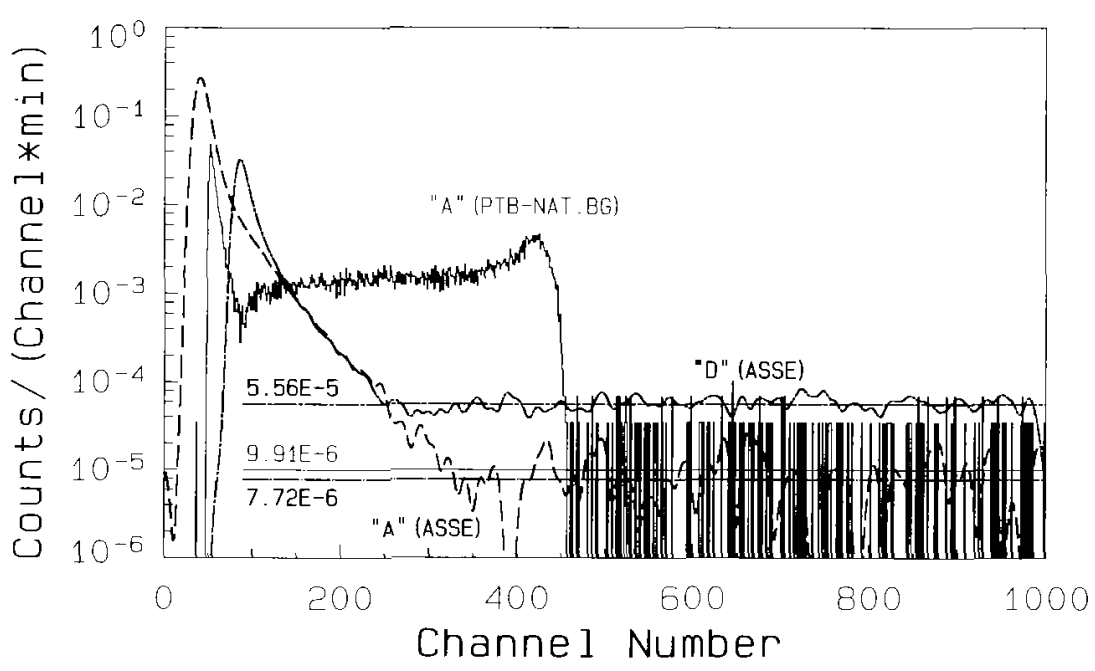

Fig. 23. - Pulse-height spectra (made distinguishable by smoothing) showing the instrumental background of two SP9 counters ("A" dot-dashed, "D" dashed, thick smooth curves), compared with the pulse-height spectrum obtained with the "A" detector (thin full-line histogram) during a measurement of the cosmic-ray induced neutron natural background on the PTB area.

Distributions de l'amplitude des impulsions (lissées pour une meilleure lisibilité du graphique) montrant le "bruit de fond instrumental" de deux compteurs SP9 ("A" trait et point, " $D$ " trait, courbes lissées épaisses), comparées avec le spectre d'amplitude obtenu avec le détecteur " $A$ " (histogramme à ligne continue mince) pendant une mesure du fond naturel de neutrons induit par le rayonnement cosmique au niveau du sol au PTB.

For comparison, the pulse-height spectrum collected with the "A" detector (thin full-line histogram) during $29138 \mathrm{~min}$ in a measurement of the cosmic-ray induced natural background on the PTB area is also given in Figure 23. By evaluating the pulse-height distributions above channel 500 , mean values of $(5.56 \pm 0.17) \times 10^{-5}$ counts/(channel-min) for the " $\mathrm{D}$ " detector in Asse, $(7.72 \pm 0.85) \times 10^{-6}$ counts/(channel.min) for the " $\mathrm{A}$ " detector in Asse and $(9.91 \pm 0.81) \times 10^{-6}$ counts/(channel.min) for the "A" detector during the natural background measurement (slightly higher than the instrumental background, due to events induced by not fully thermalised neutrons) were obtained. The contribution of the instrumental background of the "A" detector (obtained by extrapolating its pulse-height spectrum to lower channels and integrating) to count rates due to the natural background (integral fluence of about $\left.1.5 \times 10^{-2} \mathrm{~cm}^{-2} \mathrm{~s}^{-1}\right)$ is only $1.2 \%$ of the total neutron-induced events $(8.4 \%$ for detector "D"). Most of the SP9 counters investigated show instrumental background values similar to those of the " $\mathrm{A}$ " counter and are adequate for measurements in very weak neutron fields up to integral fluence values of about $10^{-4} \mathrm{~cm}^{-2} \mathrm{~s}^{-1}$ (in the best case). 


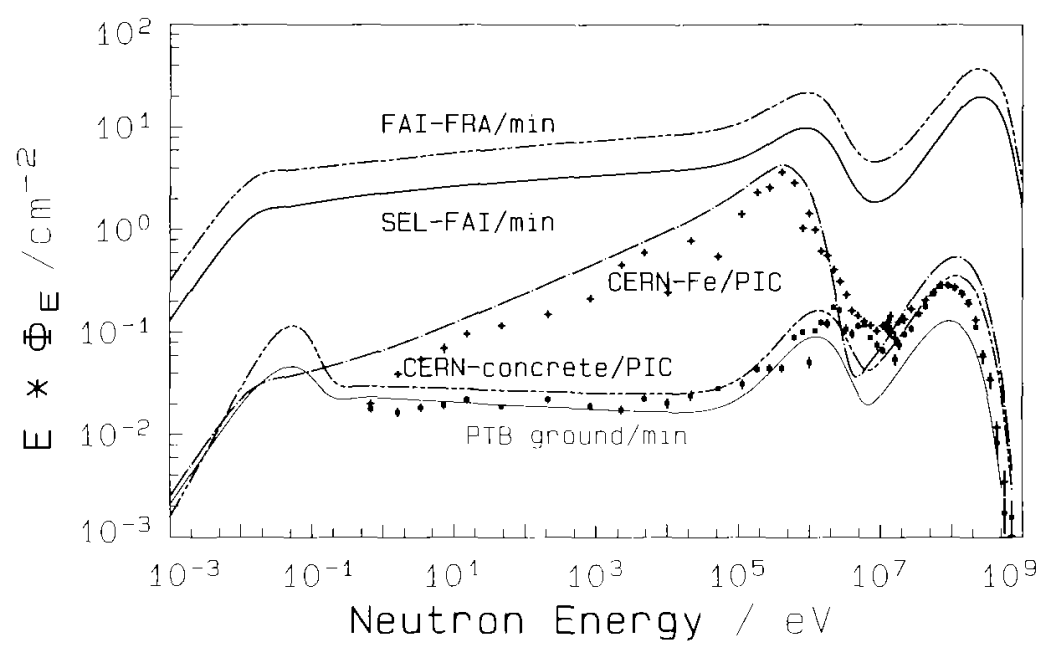

Fig. 24. - High-energy neutron spectra measured with the PTB " $C$ "BSS. For the natural background and aircraft spectra (FAI-FRA and SEL-FAI) the fluence rates are given per minute, for the two CERN spectra the fluence rates are given per monitor (PIC) pulse. FLUKA calculations of the CERN spectra (Roesler and Stevenson, 1993) are indicated by symbols.

Spectres de neutrons de hautes énergies mesurés avec le SSB PTB "C". Pour le spectre du fond naturel et ceux mesurés en avion à haute altitude (FAI-FRA et SEL-FAI) les débits de fluence spectrale sont donnés par minute, pour les deux spectres de CERN les débits de fluence sont donnés par impulsion de moniteur (PIC). Les spectres de CERN calculés avec FLUKA (Roesler and Stevenson, 1993) sont représentés par des symboles.

The spectral distribution of the cosmic-ray induced neutron natural background measured on the PTB area in Braunschweig (Alevra et al., 1997) is shown in Figure 24. For comparison, two neutron spectra are given which were measured in high-energy calibration fields produced at CERN, one behind concrete shielding, the other behind iron shielding. The CERN spectra are also compared with FLUKA calculations (Roesler and Stevenson, 1993), indicating "reasonable" agreement especially for the concrete shielding geometry. A large series of measurements could be recently performed in aircraft (Schrewe et al., 1999), due to the fact that eight BSs were used simultaneously, each detector being assisted by a miniaturised, battery-powered, electronic analog processor (Ciobanu and Alevra, 1997). Two of the spectra, measured at $10 \mathrm{~km}$ altitude, are shown in the upper part of Figure 24. The FAI-FRA $\left(70^{\circ} \mathrm{N}\right.$ geomagnetic latitude) and SEL-FAI ( $36^{\circ} \mathrm{N}$ geomagnetic latitude) spectra were measured during flights from Fairbanks to Frankfurt and Seoul to Fairbanks, respectively. From a comparison of the shapes of the spectra in Figure 24 it may be concluded that the CERN-concrete field is adequate for the calibration of dosimetric instrumentation used for monitoring the exposure to cosmic-ray-induced neutrons. 


\section{Conclusions}

Neutron field spectrometry using "portable" instruments is at present able to determine the neutron fluence with accuracies within a few percent (in the energy range $\leq 20 \mathrm{MeV}$ ) and to produce reference data for other instruments (e.g. neutron dosemeters). High energy resolutions can be attained by some spectrometers in rather limited energy ranges; in the cases where a detailed description of the neutron spectral distribution is not necessary (mostly in dosimetric applications), the moderator techniques (Bonner spheres) ensure good reliability and cover the huge energy range from thermal to a few hundreds of $\mathrm{MeV}$. Due to a very low instrumental background, the BSs are able to measure reliably low neutron fluence rates. This feature recommends them (even reduced to a set of two or three detectors) also for use as survey instruments.

Acknowledgement: The author wishes to thank Dr. Manfred Matzke, Dr. Kurt Knauf, Mr. Jürgen Wittstock and Dr. Burkhard Wiegel for their help with data and valuable suggestions. Special thanks are due to Dr. Horst Klein, important contributor to the development of the neutron spectrometry at PTB, who friendly supervised the compilation of this paper.

\section{REFERENCES}

Adams J.M., White G. (1978) A Versatile Pulse-Shape Discriminator for Charged Particle Separation and its Application to Fast Neutron Time-of-Flight Spectroscopy. Nucl. Instrum. Meth. 156, 459-476.

Alberts W.G., Bordy J.M., Chartier J.-L., Jahr R., Klein H., Luszik-Bhadra M., Posny F., Schuhmacher H., Siebert B.R.L. (1996) Neutron dosimetry. Radioprotection 31, 37-65.

Alevra A.V., Siebert B.R.L., Aroua A., Buxerolle M., Grecescu M., Matzke M., Mourgues M., Perks C.A., Schraube H., Thomas D.J., Zaborowski H. C. (1990) Unfolding of Bonner Sphere Data. A European Intercomparison of Computer Codes. Laboratory Report PTB-7.22-90-1, PTB Braunschweig / Germany.

Alevra A.V., Cosack M., Hunt J.B., Thomas D.J., Schraube H. (1992a) Experimental Determination of the Response of four Bonner Sphere Sets to Monoenergetic Neutrons (II). Radiat. Prot. Dosim. 40, $91-102$.

Alevra A.V., Matzke M., Siebert B.R.L. (1992b) Experiences from an International Unfolding Intercomparison with Bonner Spheres. In: Proceedings of the Seventh ASTM-EURATOM Symposium on Reactor Dosimetry, 27-31 August 1990, Strasbourg, France (G. Tsotridis, R. Dierckx, P. D'Hondt, Eds.), pp 215-222. Kluwer Academic Publishers, Dordrecht/Boston/London (EUR-Report 14356 EN) ISBN 0-7923-1792-0.

Alevra A.V., Klein H., Schrewe U.J. (1994) Measurements with the PTB Bonner Sphere Spectrometer in High-Energy Neutron Calibration Fields at CERN (CERN-CEC Experiment H6J93, July 1993). PTB-Report N-22, Braunschweig / Germany.

Alevra A.V. (1994) Accurate Neutron Fluence Measurements using Bonner Spheres. Reactor Dosimetry ASTM STP 1228 (Harry Farrar IV, E. Parvin Lippincott, John G. Williams, David W. Wehar, Eds.) pp 290-299. American Society for Testing and Materials, Philadelphia. 
Alevra A.V. (1995) Measurements with the PTB Bonner Sphere Spectrometer and a Leake Rem Counter. In: Determination of Neutron and Photon Dose Equivalent at Work Places in Nuclear Facilities of Sweden; An SSI-EURADOS Comparison Exercise Part 1: Measurements and Data Analysis. (H. Klein, L. Lindborg, Eds.) pp 42-58. SSI-Report 95-15, Swedish Radiation Protection Institute (ISSN 0282-4434).

Alevra A.V., Knauf K., Wittstock J. (1995) Measurements with the PTB Bonner Sphere Spectrometer and Various Dosemeters Around a Model Storage Cask Filled with a ${ }^{252}$ Cf Source both Free in Air and in a Salt Mine. PTB Laboratory Report 7.22-95-1, Braunschweig / Germany.

Alevra A.V., Schrewe U.J. (1997) Measurements with the PTB ' $\mathrm{C}$ ' Bonner Sphere Spectrometer in the PSI Villigen $55 \mathrm{MeV}$ Neutron Field for Spectrometry and Calibration Purposes. Radiat. Prot. Dosim. 70, 295-298.

Alevra A.V., Klein H., Knauf K., Wittstock J., Wolber G. (1997) Neutron Spectrometry and Dosimetry in the Environment and at Workplaces, In: Proceedings of the IRPA Regional Symposium on Radiation Protection in Neighbouring Countries of Central Europe, 8-12 September 1997, Prague. (J. Sabol, Ed.) pp 214-218. Prague.

Antunes L.J., Börker G., Klein H., Bulski G. (1986) Unfolding of the NE 213 Scintillation Spectra compared with Neutron Time-of-Flight Measurements. In: Nuclear Data for Basic and Applied Science, Vol. I, Gordon and Breach Science Publishers, New York.

Aroua A., Grecescu M., Lanfranchi M., Lerch P., Prêtre S., Valley J.-F. (1992) Evaluation and Test of the Response Matrix of a Multisphere Neutron Spectrometer in a Wide Energy Range. Part II. Simulation. Nucl. Instrum. Meth. A321, 305-311.

Bähr C., Böttger R., Klein H., v. Neumann-Cosel P., Richter A., Schmidt D., Schweda K., Strauch S. ( 1998 ) Calculation of Neutron Response Functions in Complex Geometries with the MCNP Code. Nucl. Instrum. Meth. A411, 430-436

Benjamin P.W., Kemshall C.D., Redfearn J. (1968) A High Resolution Spherical Proportional Counter. Nucl. Instrum. Meth. 59, 77-85

Bennet E.F. (1962) Gamma-Ray Discrimination in a Proton-Recoil Proportional Counter. Report ANL6480, Argone National Laboratory.

Bernatt W., Mattes M., Pfister G. (1995) Calculation of Neutron and Gamma Spectra and Dose-Rates in the Environment of the AHE-Experimental Cask on the PTB Ground. IKE-Report KE6-FB-73E, Institut für Kerntechnik und Energie-Wandlung e.V., Universität Stuttgart.

Bernnat W., Mattes M. (1995) Bestimmung von Neutronen- und Gammaspektren sowie Dosis in der Umgebung des AHE-Versuchsbehaelters innerhalb des Salzbergwerks Asse. IKE-Report KE6FB-74, Institut für Kerntechnik und Energie-Wandlung e.V., Universität Stuttgart.

Birch R. (1988) An Alpha-Recoil Proportional Counter to Measure Neutron Energy Spectra between $2 \mathrm{MeV}$ and $15 \mathrm{MeV}$. Report AERE - R - 13002, Harwell, AERE.

Bramblett R.L., Ewing R.1., Bonner T.W.(1960) A New Type of Neutron Spectrometer. Nucl. Instrum. Meth. 9, 1-12.

Bricka M., Dolias M., Lambérieux J., Caizergues, J. (1973) La Réponse des Détecteurs sous Modérateur Sphérique aux Neutrons Monocinétiques. In: Proceedings of the Symposium on Neutron Monitoring for Radiation Protection Purpose, 11-15 December 1972, Vienna. pP 279-295. IAEA, Vienna

Büermann L., Ding S., Guldbakke S., Klein H., Novotný T., Tichy M. (1993) Response of NE 213 Liquid Scintillation Detectors to High-Energy Photons (E $\gamma>3 \mathrm{MeV})$. Nucl. Instrum. Meth. A332, 483-492.

Burrus W.R., Drischler J.D. (1965) The FERDOR Unfolding Code. Report ORNL-4154, Oak Ridge.

Buxerolle M. (1971) Spectrométrie des neutrons au moyen d'un système multidétecteur. Note CEA-N-1468.

Caizergues R., Poulot G. (1972) Calcul de la réponse des Sphères de Bonner pour les détecteurs à lLi, He et Mn. Rapport CEA-R-4400.

Chartier J.-L., Posny F., Buxerolle M. (1992) Experimental Assembly for the Simulation of Realistic Neutron Spectra. Radiat. Prot. Dosim. 44, 125-130.

Chartier J.-L., Posny F. (1995) Private communication. CEA/IPSN/DPHD/S.DOS.

Ciobanu M., Alevra A.V. (1997) Low-Power Analogue Processor for Bonner Sphere Spectrometers. In: Proceedings of the IRPA Regional Symposium on Radiation Protection in Neighbouring Countries of Central Europe, 8-12 September 1997, Prague. (J. Sabol, Ed.) pp 506-509. 
Dickens J.K. (1988) SCINFUL: A Monte Carlo Based Computer Program to Determine a Scintillator Full Energy Response to Neutron Detection for En Between 0.1 and $80 \mathrm{MeV}$ : Program Development and Comparisons of Program Predictions with Experimental Data. Report ORNL6463, Oak Ridge National Laboratory, USA.

Dietze G., Klein H. (1982a) NRESP4 and NEF4 - Monte Carlo Codes for the Calculation of Neutron Response Functions and Detection Efficiencies for NE 213 Scintillation Detectors. Report PTBND-22, PTB Braunschweig / Germany.

Dietze, G., Klein H. (1982b) Gamma Calibration of NE 213 Scintillation Counters. Nucl. Instrum. Meth. 193, 549-556.

Ing H., Clifford T., McLean T., Webb W., Cousins T., Dhermain J. (1997) ROSPEC: a Simple Reliable High-Resolution Neutron Spectrometer. Radiat. Prot. Dosim. 70, 273-278.

International Commission on Radiological Protection (1973) Data for Protection against Radiation from External Sources: Supplement to ICRP Publication I5. ICRP Publication 21, Pergamon Press, Oxford.

International Commission on Radiological Protection (1997) Conversion Coefficients for use in Radiological Protection against External Radiation (Adopted by the ICRP and ICRU in September 1995), ICRP Publication 74, Pergamon Press, Oxford.

Klein H. (1997) Workplace Radiation Field Analysis. Radiat. Prot. Dosim. 70, 225-234.

Knauf K., Alevra A.V., Klein H., Wittstock J. (1989) Neutronenspektrometrie im Strahlenschutz. PTBMitteilungen 99, 101-106.

Knauf K., Wittstock J. (1997) Private communication. PTB Braunschweig.

Knauf K., Heimann C., Kaldune N., Novotny T., Wittstock J. (1997) Spectrometry in a Mixed NeutronPhoton Field, a Field Experiment within the Framework of the AHE Project using a Liquid Scintillation Counter and Spherical Proton Recoil Proportional Counters. Laboratory Report PTB-6.42-97-2, PTB Braunschweig / Germany.

Knauf K., Kaldune N., Plewnia A., Simon F., Weyrauch M. (1998) SPHERE, A Program Package for Calculating the Response of Spherical Proton-Recoil Proportional Counters. Laboratory Report PTB-6-42-98-1, Braunschweig / Germany.

Matzke, M. (1994) Unfolding of Pulse-Height Spectra: The HEPRO Program system. Report PTB-N-19, PTB Braunschweig / Germany.

Matzke M. (1997) Unfolding of Particle Spectra. In: Proceedings of the 5th International Conference on Neutrons in Research and Industry, June 9 - 15, 1996, Crete, Greece. (Vourvopoulos G., Ed.), pp 598-607. Proc. SPIE 2867, ISBN 0-8194-2263-0.

McElroy W.N., Berg S., Crockett T., Hawkins R.G. (1967) Sand-II, a Computer-Automated Iterative Method for Neutron Flux Spectra Determination by Foil Activation. Report AFWL-TR-67-41., Vol. I-IV, U.S. Air Force Weapons Laboratory, New Mexico.

Mourgues M. (1975) La Mesure des Neutrons par Compteur à Helium-3 sous Modérateur Sphèrique. In: Proceedings of the Symposium on Neutron Dosimetry in Biology and Medicine, Sept. 30 Oct. 4, 1974, Neuherberg/München. Vol II, pp 907-931, EUR-5273, Luxembourg.

Mourgues M. (1984) Ensemble de détection par sphères modératrices et compteur à hélium-3 pour la dosimétrie et la spectrométrie des neutrons. Rapport d'Etude CEA, CEN Cadarache.

Nolte R., Brede H.J., Schrewe U.J., Schuhmacher H. (1993) Neutron Spectrometry with Liquid Scintillation Detectors at Neutron Energies between $20 \mathrm{MeV}$ and $70 \mathrm{MeV}$ : A Status Report. Report PTBN-9, РТВ Braunschweig / Germany.

Novotný T. (1997) Photon Spectrometry in Mixed Neutron-Photon Fields using the Liquid Scintillator NE 213. Thesis, Prague 1996 and Report PTB-ND-28, PTB Braunschweig / Germany.

Perey F.G. (1977) Least-Squares Dosimetry Unfolding; The Program STAY'SL. Report ORNL / TM6062, Oak Ridge National Laboratory, USA.

Roesler S., Stevenson G.R. (1993) July 1993 CERN-CEC Experiments: Calculation of Hadron Energy Spectra from Track-Length Distributions using Fluka. CERN/TIS-RP/IR/93-47.

Schmidt D., Chenwei Z. (1997) Long-term Stability of a Neutron Detector. Laboratory Report PTB6.42-97-1, PTB Braunschweig / Germany. 


\section{NEUTRON SPECTROMETRY}

Schrewe U.J., Alberts W.G., Alevra A.V., Ferrari A., Otto T., Silari M. (1999) Calibration Problems, Calibration Procedures and Reference Fields. In: Proceedings of the International Conference on Cosmic Radiation and Air Crew Exposure, 1-3 July 1998, Dublin, Ireland. Radiat. Prot. Dosim. (accepted for publication).

Schuhmacher H., Alberts W.G., Alevra A.V., Klein H., Schrewe U.J., Siebert B.R.L. (1995) Characterisation of Photon-Neutron Radiation Protection Monitoring and Optimisation. Radiat. Prot. Dosim. 61, 81-88.

Siebert B.R.L., Schuhmacher H. (1995) Quality Factors, Ambient and Personal Dose Equivalent for Neutrons, Based on the New ICRU Stopping Power Data for Protons and Alpha Particles. Radiat. Prot. Dosim. 58, 177-183.

Thomas D.J. (1992) Use of the Program ANISN to Calculate Response Functions for a Bonner Sphere Set with ${ }^{3}$ He Detector. Report RSA(EXT)31, National Physical Laboratory, Teddington, UK.

Thomas D.J., Alevra A.V., Hunt J.B., Schraube H. (1994) Experimental Determination of the Response of four Bonner Sphere Sets to Thermal Neutrons. Radiat. Prot. Dosim. 54, 25-31.

Thomas D.J., Chartier J.-L., Klein H., Naismith O.F., Posny F., Taylor G.C. (1997) Results of a Large Scale Neutron Spectrometry and Dosimetry Comparison Exercise at the Cadarache Moderator Assembly. Radiat. Prot. Dosim. 70,313-322.

Thomas P.M., Harrison K.G., Scott M.C. (1984) A Multisphere Neutron Spectrometer Using a Central ${ }^{3}$ He Detector. Nucl. Instrum. Meth. 224, 225-232.

Tichy M. (1988) Bayesian Approach to Neutron Spectrum Adjustment. Nucl. Instrum. Meth. A267, 502508.

Tichy M. (1993) The DIFBAS Program - Description and User's Guide. PTB Laboratory Report 7.293-1, Braunschweig / Germany.

Verbinski V.V., Burrus W.R., Love T.A., Zobel W., Hill N.W., Textor R. (1968) Calibration of an Organic Scintillator for Neutron Spectrometry. Nucl. Instrum. Meth. 65, 8-25.

Weise K., Weyrauch M., Knauf K. (1991) Neutron Response of a Spherical Proportional Counter. Nucl. Instrum. Meth. A309, 287-293.

Weise K. (1995) Mathematical Foundation of an Analytical Approach to Bayesian-Statistical Monte Carlo Spectrum Unfolding. Report PTB-N-24, Physikalisch-Technische Bundesanstalt, Braunschweig / Germany.

Weyrauch M., Knauf K. (1992) Absolute Neutron Fluence Determination with a Spherical Proton-Recoil Proportional Counter. Radiat. Prot. Dosim. 44, 97-99.

Weyrauch M., Casnati A., Schillebeeckx P., Clapham M. (1998) Use of ${ }^{4}$ He-Filled Proportional Counters as Neutron Spectrometers. Nucl. Instrum. Meth. A403, 442-454

Wiegel B., Alevra A.V., Siebert B.R.L. (1994) Calculations of the Response Functions of Bonner Spheres with a Spherical ${ }^{3}$ He Proportional Counter using a Realistic Detector Model. PTB Report N-21, Braunschweig / Germany.

Zaborowski H.L. (1981) Dosimétrie et Spectrométrie Neutroniques avec les Sphères de Bonner; Etablissement d'une Matrice Log-Normale de Référence. Note CEA-N-2241 and In: Proceedings of the Fourth Symposium on Neutron Dosimetry, 1-5 June 1981, Neuherberg/München, Vol. I. pp 575-587. EUR-7448 En. 